\title{
Myeloproliferative neoplasms with concurrent $B C R-A B L 1$ translocation and JAK2 V617F mutation: a multi-institutional study from the bone marrow pathology group
}

Craig R Soderquist ${ }^{1,9}$, Mark D Ewalt ${ }^{2}$, David R Czuchlewski ${ }^{3}$, Julia T Geyer ${ }^{4}$, Heesun J Rogers ${ }^{5}$, Eric D Hsi ${ }^{5}$, Sa A Wang ${ }^{6}$, Carlos E Bueso-Ramos ${ }^{6}$, Attilio Orazi ${ }^{4}$, Daniel A Arber ${ }^{7}$, Elizabeth O Hexner ${ }^{8}$, Daria V Babushok ${ }^{8}$ and Adam Bagg ${ }^{1}$

${ }^{1}$ Department of Pathology and Laboratory Medicine, University of Pennsylvania, Philadelphia, PA, USA; ${ }^{2}$ Department of Pathology, University of Colorado, Denver, CO, USA; ${ }^{3}$ Department of Pathology, University of New Mexico, Albuquerque, NM, USA; ${ }^{4}$ Department of Pathology and Laboratory Medicine, Weill Cornell Medical College, New York, NY, USA; ${ }^{5}$ Department of Laboratory Medicine, Cleveland Clinic, Cleveland, OH, USA; ${ }^{6}$ Department of Hematopathology, MD Anderson Cancer Center, Houston, TX, USA; ${ }^{7}$ Department of Pathology, University of Chicago, Chicago, IL, USA and ${ }^{8}$ Divisionof Hematology and Oncology, Department of Medicine, University of Pennsylvania, Philadelphia, PA, USA

Myeloproliferative neoplasms arise from hematopoietic stem cells with somatically altered tyrosine kinase signaling. Classification of myeloproliferative neoplasms is based on hematologic, histopathologic and molecular characteristics including the presence of the BCR-ABL1 and JAK2 V617F. Although thought to be mutually exclusive, a number of cases with co-occurring $B C R-A B L 1$ and JAK2 V617F have been identified. To characterize the clinicopathologic features of myeloproliferative neoplasms with concomitant $B C R-A B L 1$ and JAK2 V617F, and define the frequency of co-occurrence, we conducted a retrospective multi-institutional study. Cases were identified using a search of electronic databases over a decade at six major institutions. Of 1570 patients who were tested for both $B C R-A B L 1$ and JAK2 V617F, six were positive for both. An additional five patients were identified via clinical records providing a total of 11 cases for detailed evaluation. For each case, clinical variables, hematologic and genetic data, and bone marrow histomorphologic features were analyzed. The sequence of identification of the genetic abnormalities varied: five patients were initially diagnosed with a JAK2 $\mathrm{V} 617 \mathrm{~F}+$ myeloproliferative neoplasm, one patient initially had $B C R-A B L 1+$ chronic myeloid leukemia, while both alterations were identified simultaneously in five patients. Classification of the BCR-ABL1-negative myeloproliferative neoplasms varied, and in some cases, features only became apparent following tyrosine kinase inhibitor therapy. Seven of the 11 patients showed myelofibrosis, in some cases before identification of the second genetic alteration. Our data, reflecting the largest reported study comprehensively detailing clinicopathologic features and response to therapy, show that the co-occurrence of $B C R-A B L 1$ and JAK2 V617F is rare, with an estimated frequency of $0.4 \%$, and most often reflects two distinct ('composite') myeloproliferative neoplasms. Although uncommon, it is important to be aware of this potentially confounding genetic combination, lest these features be misinterpreted to reflect resistance to therapy or disease progression, considerations that could lead to inappropriate management.

Modern Pathology (2018) 31, 690-704; doi:10.1038/modpathol.2017.182; published online 12 January 2018

Correspondence: Dr CR Soderquist, MD, Division of Hematopathology, Department of Pathology and Cell Biology, Columbia University Medical Center, 630 West 168th Street, VC 14-240, New York, NY 10032, USA.

E-mail: csoderquist2@gmail.com

${ }^{9}$ Current affiliation: Department of Pathology and Cell Biology, Columbia University, New York, NY, USA.

Received 1 June 2017; revised 22 October 2017; accepted 26 October 2017; published online 12 January 2018
Myeloproliferative neoplasms arise from hematopoietic stem cells with somatically acquired tyrosine kinase alterations, which activate signaling pathways leading to heightened cellular proliferation. The BCR-ABL1 translocation and JAK2, CALR and $M P L$ alterations have dominant roles in myeloproliferative neoplasm pathogenesis; accordingly, identification of these specific genetic alterations has been 
Table 1 Clinical and pathologic features, and response to therapy in patients with BCR-ABL1+, JAK2 V617+ myeloproliferative neoplasms

\begin{tabular}{|c|c|c|c|c|c|c|c|c|c|c|c|c|c|c|c|c|c|c|c|c|c|c|c|c|c|c|}
\hline \multirow[b]{2}{*}{ Pt \# } & \multirow[b]{2}{*}{ Sex } & \multirow[b]{2}{*}{ Age } & \multicolumn{4}{|c|}{ Initial neoplasm } & \multicolumn{10}{|c|}{ Composite $(B C R-A B L 1+, J A K 2 \mathrm{~V} 617 F+) M P N$} & \multicolumn{10}{|c|}{ Response to treatment of composite $(B C R-A B L 1+, J A K 2 \mathrm{~V} 617 F+) M P N$} \\
\hline & & & Initial $D x$ & $\begin{array}{c}B C R- \\
A B L 1 \\
(+/-)\end{array}$ & $\begin{array}{c}J A K 2 \\
\text { V617F } \\
(+/-) \\
\text { Spec } \\
\text { type }\end{array}$ & $\begin{array}{c}\text { Initial } \\
T_{X}\end{array}$ & $\begin{array}{c}\text { Time } \\
\text { to } D x \\
\text { (mo) }\end{array}$ & $\begin{array}{c}\text { MPN } \\
\text { Hist } \\
\text { features }\end{array}$ & $\begin{array}{c}\text { WBC } \\
\left(\times 10^{3}\right) \\
\mu l)\end{array}$ & $\begin{array}{l}H g b \\
(g / \\
d l)\end{array}$ & $\begin{array}{c}P l t \\
\left(x 10^{3} /\right. \\
\mu l)\end{array}$ & $\begin{array}{c}B C R- \\
A B L 1 \\
(+/-)\end{array}$ & $\begin{array}{c}t(9 ; 22) \\
(\%+)\end{array}$ & $\begin{array}{l}\text { FISH } \\
(\%+)\end{array}$ & $\begin{array}{c}J A K 2 \\
\text { V617F } \\
(+/-) \\
\text { Spec } \\
\text { type }\end{array}$ & $\begin{array}{c}J A K 2 \\
\text { Mut } \\
\text { allele } \\
\text { (\%) }\end{array}$ & $\begin{array}{l}F / U \\
\text { time } \\
\text { (mo) }\end{array}$ & $T x$ & $\begin{array}{c}\text { WBC } \\
\left(\times 10^{3} /\right. \\
\mu l)\end{array}$ & $\begin{array}{l}H g b \\
(g / \\
d l)\end{array}$ & $\begin{array}{c}\text { Plt } \\
\left(\times 10^{3} /\right. \\
\mu l)\end{array}$ & $M M R$ & $\begin{array}{c}J A K 2 \\
\text { V617F } \\
(+/-) \\
\text { Spec } \\
\text { type }\end{array}$ & $\begin{array}{c}\text { JAK2 } \\
\text { Mut } \\
\text { allele } \\
\text { (\%) }\end{array}$ & Course & $\begin{array}{c}\text { Alive } \\
\text { dead }\end{array}$ \\
\hline 1 & $\mathrm{~F}$ & 48 & PMF & - & $+\mathrm{PB}^{\mathrm{a}}$ & None & 129 & CML & 142 & 8.3 & 557 & $+\mathrm{e} 13 \mathrm{a} 2$ & 100 & 94 & $+\mathrm{BM}$ & $10-50$ & 48 & $\begin{array}{l}\text { Nil, } \\
\text { Hy, }\end{array}$ & 5.9 & 9.3 & 141 & Yes & $+\mathrm{BM}$ & 78 & MF & A \\
\hline 2 & $\mathrm{~F}$ & 66 & ET & - & $+\mathrm{BM}$ & $\begin{array}{l}\text { Hy, } \\
\text { Rux }\end{array}$ & 45 & $\begin{array}{l}\text { Post-ET } \\
\text { MF; } \\
\text { CML }\end{array}$ & 42.0 & 10.2 & 38 & + e13a2 & 80 & ND & $+\mathrm{BM}$ & 24.0 & 23 & $\begin{array}{l}\text { Im, } \\
\text { Bos, } \\
\text { Rux }\end{array}$ & 12.5 & 10.1 & 39 & No & ND & ND & $\mathrm{MF}$ & A \\
\hline 3 & $\mathrm{~F}$ & 48 & PV & - & $+\mathrm{BM}$ & $\begin{array}{l}\text { Phleb, } \\
\text { Hy, } \\
\text { IFN }\end{array}$ & 58 & $\begin{array}{l}\text { Post-PV } \\
\text { MF; } \\
\text { CML }\end{array}$ & 26.1 & 13.4 & 66 & $+\mathrm{e} 13 \mathrm{a} 2$ & 100 & ND & $+\mathrm{BM}$ & 24.4 & 25 & $\begin{array}{l}\text { Im, } \\
\text { IFN, } \\
\text { Rux }\end{array}$ & 16.1 & 13.9 & 190 & No & ND & ND & MF & A \\
\hline 4 & $\mathrm{~F}$ & 60 & PV & - & $+\mathrm{PB}$ & $\begin{array}{l}\text { Hy, } \\
\text { Th, } \\
\text { Rux }\end{array}$ & 107 & $\begin{array}{l}\text { Post-PV } \\
\text { MF; } \\
\text { CML }\end{array}$ & 60.2 & 8.8 & 77 & $+\mathrm{e} 1 \mathrm{a} 2$ & 80 & 63 & $+\mathrm{PB}$ & $>50$ & 6 & $\begin{array}{l}\text { Im, } \\
\text { Hy, } \\
\text { Th, } \\
\text { Rux }\end{array}$ & 17.4 & 8.6 & 92 & No & ND & ND & MF & $\mathrm{D}$ \\
\hline 5 & $\mathrm{M}$ & 76 & PV & - & $\mathrm{ND}^{\mathrm{b}}$ & Hy & 73 & $\begin{array}{l}\text { CML } \\
\text { (AP) }\end{array}$ & 23.3 & 10 & 32 & $+\mathrm{e} 1 \mathrm{a} 2$ & 100 & 82 & $+\mathrm{PB}$ & $<10$ & 4 & $\begin{array}{l}\text { Im, } \\
\text { Hy }\end{array}$ & 25.4 & 8.5 & 86 & No & $+\mathrm{PB}$ & $<10$ & $\begin{array}{l}\text { CML } \\
\text { (AP) }\end{array}$ & $\mathrm{D}$ \\
\hline 6 & $\mathrm{~F}$ & 49 & CML & + & ND & Im IFN & 109 & $\begin{array}{l}\text { MPN, } \\
\text { NOS }\end{array}$ & 6.9 & 12.1 & 858 & $+\mathrm{e} 14 \mathrm{a} 2$ & - & ND & $+\mathrm{BM}$ & ND & 68 & $\begin{array}{l}\text { Im, } \\
\text { Das }\end{array}$ & 18.0 & 10.1 & 114 & No & $+\mathrm{BM}$ & 28 & $\mathrm{MF}$ & A \\
\hline 7 & $\mathrm{M}$ & 70 & $\mathrm{NA}$ & NA & NA & NA & NA & $\begin{array}{l}\text { CML; } \\
\text { MF }\end{array}$ & 18.5 & 11.7 & 389 & $+\mathrm{e} 14 \mathrm{a} 2$ & 60 & ND & $+\mathrm{BM}$ & ND & 76 & $\begin{array}{l}\text { Im, } \\
\text { Nil, } \\
\text { Das, } \\
\text { Hy } \\
\text { Rad }\end{array}$ & 20.0 & NA & NA & No & $+\mathrm{PB}$ & 7.6 & MF & D \\
\hline 8 & M & 68 & NA & NA & NA & NA & NA & CML & 13.1 & 13.6 & 670 & $+\mathrm{e} 14 \mathrm{a} 2$ & 95 & ND & $+\mathrm{BM}$ & $<10$ & 43 & $\begin{array}{l}\text { Im, } \\
\text { Das, } \\
\text { An }\end{array}$ & 7.2 & 11.0 & 554 & Yes & $+\mathrm{BM}$ & $>25$ & Rem & A \\
\hline 9 & M & 49 & NA & NA & NA & NA & NA & $\begin{array}{l}\text { CML; } \\
\text { MF }\end{array}$ & 72.9 & 9.7 & 268 & $+\mathrm{e} 14 \mathrm{a} 2$ & 100 & ND & $+\mathrm{PB}$ & ND & 32 & $\begin{array}{l}\text { Im, } \\
\text { Das, } \\
\text { Allo }\end{array}$ & 35.9 & 11.8 & 91 & Yes & - BM & $<1$ & $\begin{array}{l}\text { CML } \\
\text { (AP) }\end{array}$ & D \\
\hline 10 & $\mathrm{~F}$ & 81 & NA & NA & NA & NA & NA & $\begin{array}{c}\text { CML; } \\
\text { ET }\end{array}$ & 15.7 & 13.2 & 351 & $+\mathrm{e} 14 \mathrm{a} 2$ & 75 & ND & $+\mathrm{BM}$ & 18.3 & 109 & $\begin{array}{l}\text { Im, } \\
\text { Nil, } \\
\text { An, } \\
\text { Hy }\end{array}$ & 15.2 & 9.4 & 189 & No & ND & ND & $\begin{array}{l}\mathrm{MF} \\
\mathrm{CML} \\
\text { (BP) }\end{array}$ & $\mathrm{D}$ \\
\hline 11 & $\mathrm{~F}$ & 73 & $\mathrm{NA}$ & NA & NA & NA & NA & $\begin{array}{l}\text { CML; } \\
\text { PV }\end{array}$ & 12.8 & 13.3 & 432 & $+\mathrm{e} 1 \mathrm{a} 2$ & 10 & 5 & $+\mathrm{BM}$ & ND & 17 & $\begin{array}{l}\text { Im, } \\
\text { Phleb }\end{array}$ & 14.5 & 12.5 & 409 & No & $+\mathrm{PB}$ & ND & Rem & A \\
\hline
\end{tabular}

Abbreviations: +, positive; -, negative; A, alive; Allo, allogeneic stem cell transplant; An, anagrelide; AP, accelerated phase; BP, blast phase; BM, bone marrow; Bos, bosutinib; CML, chronic myeloid leukemia; D, dead; Das, dasatinib; Dx, diagnosis; ET, essential thrombocythemia; F, female; F/U, follow-up; Hgb, hemoglobin; Hist, histologic; Hy, hydroxyurea; IFN, interferon- $\alpha$; Im, imatinib mesylate; M, male; Mo, months; MF, myelofibrosis; MMR, major molecular response; MPN, NOS, myeloproliferative neoplasm, not otherwise specified; Nil, nilotinib; NA, not applicable; ND, not determined; PB, peripheral blood; Phleb, therapeutic phlebotomy; Plt, platelet count; PMF, primary myelofibrosis; PV, polycythemia vera; Rad, radiation; Rem, remission; Rux, ruxolitinib; Th, thalidomide; Tx, treatment; WBC, white blood cell count.

Testing perforned subsequent to initial diagnosis, but before evidence of CML emerged.

${ }^{b}$ Patient diagnosed with PV before 2005 based on laboratory, hematologic and histopathologic criteria.

Group 1: JAK2 V617F detected first, BCR-ABL1 second. Group 2: BCR-ABL1 detected first, JAK2 V617F second. Group 3: BCR-ABL1 and JAK2 V617F detected simultaneously. 
incorporated into WHO diagnostic criteria. The $B C R-A B L 1$ translocation is requisite in the development and diagnosis of chronic myeloid leukemia. On the other hand, the gain-of-function JAK2 V617F mutation drives disease but has a less directly defined mechanistic relationship across myeloproliferative neoplasm phenotypes. It nevertheless has an essential diagnostic role and is variably identified in polycythemia vera $(\sim 95 \%)$, primary myelofibrosis $(\sim 60 \%)$ and essential thrombocythemia $(\sim 50 \%))^{1,2}$

Recently, several isolated case reports ${ }^{3-24}$ and small case series ${ }^{25-36}$ have described patients with co-occurring JAK2 V617F and BCR-ABL1. As a result of the inherently small sample size in prior reports, the frequency of co-occurrence, the temporal order of acquisition and clonal relationship of these alterations remain poorly understood. Furthermore, there is a lack of a systematic analysis of the clinical presentation, hematologic findings and histopathologic features of patients with these neoplasms, frequently leading to diagnostic and therapeutic uncertainty in this patient population. To address these unknowns, we performed a multi-institutional study of patients evaluated for a suspected myeloproliferative neoplasm at six major academic medical centers. Here we present the unique features of 11 cases found to be both $J A K 2 \mathrm{~V} 617 \mathrm{~F}$ and $B C R-A B L 1$ positive.

\section{Materials and methods}

\section{Patient Population}

Patients were identified through a combination of systematic search of pathology databases, as well as clinical record review. We searched molecular and anatomic pathology databases from three of the six participating institutions for patients with suspected myeloproliferative neoplasm who underwent molecular testing for both JAK2 V617F and BCR-ABL1 over a 10-year period, between July 2005 and June 2015. Additional patients with $J A K 2+B C R-A B L 1+$ myeloproliferative neoplasm were identified via review of clinical records from the other three institutions. Case 7 has previously been reported ${ }^{27}$ and the morphologic features of case 8 were highlighted in an image-based publication. ${ }^{37}$ Institutional review board approval was obtained at all participating institutions.

\section{BCR-ABL1 and JAK2 V617F Mutation Detection}

$\mathrm{t}(9 ; 22)$ and/or BCR-ABL1 analysis was performed by routine metaphase cytogenetics, reverse transcription polymerase chain reaction and fluorescent insitu hybridization according to standard operating protocols for clinical diagnosis. JAK2 V617F mutation was detected by an allelic discrimination assay or DNA sequencing on either bone marrow or peripheral blood specimens (Table 1). When archival specimens were accessible, molecular testing was retrospectively performed at earlier time points in an attempt to determine when specific molecular alterations might have been acquired.

\section{Clinicopathologic Analysis}

For each patient with concurrent $J A K 2 \mathrm{~V} 617 \mathrm{~F}$ and $B C R-A B L 1$, demographic (age and gender), clinical, hematologic (peripheral blood counts), genetic (cytogenetic profile and molecular genetic results) and bone marrow histomorphologic features were acquired at diagnosis and follow-up. When histologic material was still available, the authors reviewed the cases from their institution in order to confirm, clarify and expand upon the reported histomorphologic findings. As this was a retrospective study, treatment decisions (therapy received, dosage) were based on the practice of each institution. Treatments included first-, second- and third-generation tyrosine kinase inhibitors, interferon, JAK inhibitors, hydroxyurea, anagrelide, thalidomide, therapeutic phlebotomy and allogeneic stem cell transplant. Outcome measures (response to therapy and survival) were measured from time of diagnosis of each neoplasm.

\section{Results}

\section{Patient Characteristics}

Of 1570 patients (from three institutions) who had a suspected myeloproliferative neoplasm and were tested concurrently for $B C R-A B L 1$ and JAK2 V617F, $105(6.7 \%)$ tested positive for $B C R-A B L 1$ only, $454(28.9 \%)$ tested positive for JAK2 V617F only, whereas $6(0.4 \%)$ tested positive for both. Over the same time period, with data only available from two institutions, 1695 patients were tested for $B C R-$ $A B L 1$ only, of whom $659(38.9 \%)$ tested positive while in 2437 patients who were tested for JAK2 V617F only, $732(30.0 \%)$ tested positive.

In addition to these patients identified via search of pathology databases, five more patients were identified via review of clinical records, for a total of 11 patients (Table 1). Four of the patients were male, seven were female. The median age at initial diagnosis was 66 years (range 48-81 years). Three patients had a history of prior and/or concurrent non-hematopoietic neoplasm, one of whom received radiation therapy.

\section{Molecular Findings at Initial Presentation}

Of the 11 patients with co-occurring JAK2 $\mathrm{V} 617 \mathrm{~F}$ and $B C R-A B L 1$, six had a single molecular alteration identified at initial myeloproliferative neoplasm diagnosis, with the second alteration identified at a later time point. The mean time to detection of the second alteration was 87 months (range 45129 months). In the majority of cases (five of six), 
a JAK2 $\mathrm{V} 617 \mathrm{~F}+$ myeloproliferative neoplasm was diagnosed before detection of $B C R-A B L 1$. In each case, an initial $B C R-A B L 1$ assay was negative. One patient had documented $B C R-A B L 1+$ chronic myeloid leukemia with the identification of $J A K 2 \mathrm{~V} 617 \mathrm{~F}$ occurring at a later date, though this patient had no $J A K 2$ study performed at the initial diagnosis of chronic myeloid leukemia and retrospective analysis could not be performed. Both JAK2 V617F and BCR$A B L 1$ were identified simultaneously in the remaining five patients.

Based on the time course of the identified abnormalities, the cases can thus be categorized into three groups: Group $1=5$ patients (patients 1-5) with $J A K 2+$ myeloproliferative neoplasm who subsequently acquired $B C R-A B L 1$; Group $2=1$ patient (patient 6) with $B C R-A B L 1+$ chronic myeloid leukemia with JAK2 V617F detected subsequently; and Group $3=5$ patients (patients 7-11) who had both $B C R-A B L 1$ and JAK2 V617F identified simultaneously at initial diagnosis. The findings in these three groups are presented in detail below. Laboratory and histopathologic features of representative patients from each group are highlighted in Figures 1,2,3,4; laboratory and molecular parameters at specific time points are highlighted in Table 1.

\section{Group 1: JAK2 V617F Detected First, BCR-ABL1 Second (Patients 1-5)}

Laboratory findings and treatment during JAK2+ myeloproliferative neoplasm disease phase. Of the five patients who initially presented with JAK2 $\mathrm{V} 617 \mathrm{~F}+$ myeloproliferative neoplasm, one (patient 1) had primary myelofibrosis, one (patient 2) had essential thrombocythemia and three (patients 3-5) had polycythemia vera. The mean time to identification of $B C R-A B L 1$ was 82 months (range 45129 months). Four patients (patients 2-5) underwent cytoreductive treatment with hydroxyurea. Patients 2 and 4 additionally received ruxolitinib. Interferonalpha was administered to patient 3 and thalidomide was administered to patient 4 . Patient 1 received no therapy. Response to therapy varied, but JAK2 V617F remained detectable in those patients tested.

Bone marrow histology during JAK2+ myeloproliferative neoplasm disease phase. Bone marrow findings before acquisition of $B C R-A B L 1$ were compatible with the diagnosed Ph-negative myeloproliferative neoplasm. Per diagnostic pathology reports, those patients with polycythemia vera showed hypercellularity with panmyelosis. Patients 3 and 4 progressed to post-polycythemic myelofibrosis before identification of $B C R-A B L 1$. The patient with essential thrombocythemia additionally showed progression to post-essential thrombocythemia myelofibrosis. Of note, all three patients with myelofibrosis had concurrent negative $B C R-A B L 1$ testing at the time myelofibrosis was noted. Patient 1 was initially diagnosed with primary myelofibrosis over 10 years before acquisition of $B C R-A B L 1$. In no case were there any overt histomorphologic harbingers that might have been predictive of the subsequent development of chronic myeloid leukemia.

Laboratory hematology findings at time of identification of $B C R-A B L 1$. In all patients, complete blood counts revealed an increase in the WBC count at the time of $B C R-A B L 1$ acquisition (see patient 1, Figure 1) from a mean baseline of $16.7 \times 10^{3} / \mu \mathrm{l}$ (range $6.3-31.6 \times 10^{3} / \mu \mathrm{l}$ ) to a mean WBC of $58.7 \times 10^{3} / \mu$ l (range $23.3-142 \times 10^{3} / \mu \mathrm{l}$ ). Patients 1,2 and 4 showed circulating myeloid precursors with basophilia. Patient 3 showed only peripheral neutrophilia without left-shift and patient 5 showed granulocytes in all phases of maturation with increased numbers of circulating myeloblasts, which prompted a bone marrow study that showed leftshifted granulocytic hyperplasia and $10-15 \%$ blasts. The blasts displayed a myeloid immunophenotype. Patients 2-5 showed progressive thrombocytopenia, (mean $53 \times 10^{3} / \mu \mathrm{l}$; range $32-77 \times 10^{3} / \mu \mathrm{l}$, decreased from baseline mean $230 \times 10^{3} / \mu \mathrm{l}$; range $88-349 \times 10^{3} /$ $\mu l)$, though three of these patients had known prior progression to myelofibrosis. Among these same four patients, hemoglobin levels dropped from a mean of $12.3 \mathrm{~g} / \mathrm{dl}$ (range 8.4-15.2 g/ $\mathrm{dl}$ ) to $10.6 \mathrm{~g} / \mathrm{dl}$ (range 8.3$13.4 \mathrm{~g} / \mathrm{dl}$ ). Patient 1 showed new onset thrombocytosis $\left(557 \times 10^{3} / \mu \mathrm{l}\right.$, increased from $\left.349 \times 10^{3} / \mu \mathrm{l}\right)$ and anemia (Hgb: $8.3 \mathrm{~g} / \mathrm{dl}$, decreased from $13.8 \mathrm{~g} / \mathrm{dl}$ ).

Genetic findings at time of identification of BCR$A B L 1$. Patients 2-5 were undergoing treatment for the $J A K 2+$ myeloproliferative neoplasm at the time of $B C R-A B L 1$ identification, with a range of mutant $J A K 2$ V617F allele levels detected. Patient 4 had a JAK2 $\mathrm{V} 617 \mathrm{~F}$ mutant allele frequency of $>50 \%$, patients 1-3 had mutant allele frequencies between 10 and $50 \%$, whereas patient 5 had a mutant allele burden of $<10 \%$. All five patients displayed high levels of $\mathrm{t}(9 ; 22)$ and/or $B C R-A B L 1$-positive cells at this phase of their disease with bone marrow cytogenetic studies showing $t(9 ; 22)$ in a mean of $86 \%$ metaphases (range $80-100 \%$ ), whereas FISH showed a mean of $76 \%$ positive cells (range 63-94\%) in the three patients tested. All patients had BCRABL1 transcripts detected by qualitative RT-PCR; patients 4 and 5 showed the e1a2 transcript only (Table 1).

Bone marrow histology at time of identification of $B C R-A B L 1$. Patients 2-4 had shown increased reticulin fibrosis (two myelofibrosis grade $2 / 3$, one myelofibrosis grade $3 / 3$ ) before detection of $B C R-$ $A B L 1$. Upon acquisition of $B C R-A B L 1$, bone marrow histology in all five cases showed morphologic features that were generally consistent with, and in some cases essentially indistinguishable from, those seen in chronic myeloid leukemia (Figure 1), though in cases 2-4 there was persistent fibrosis. All 

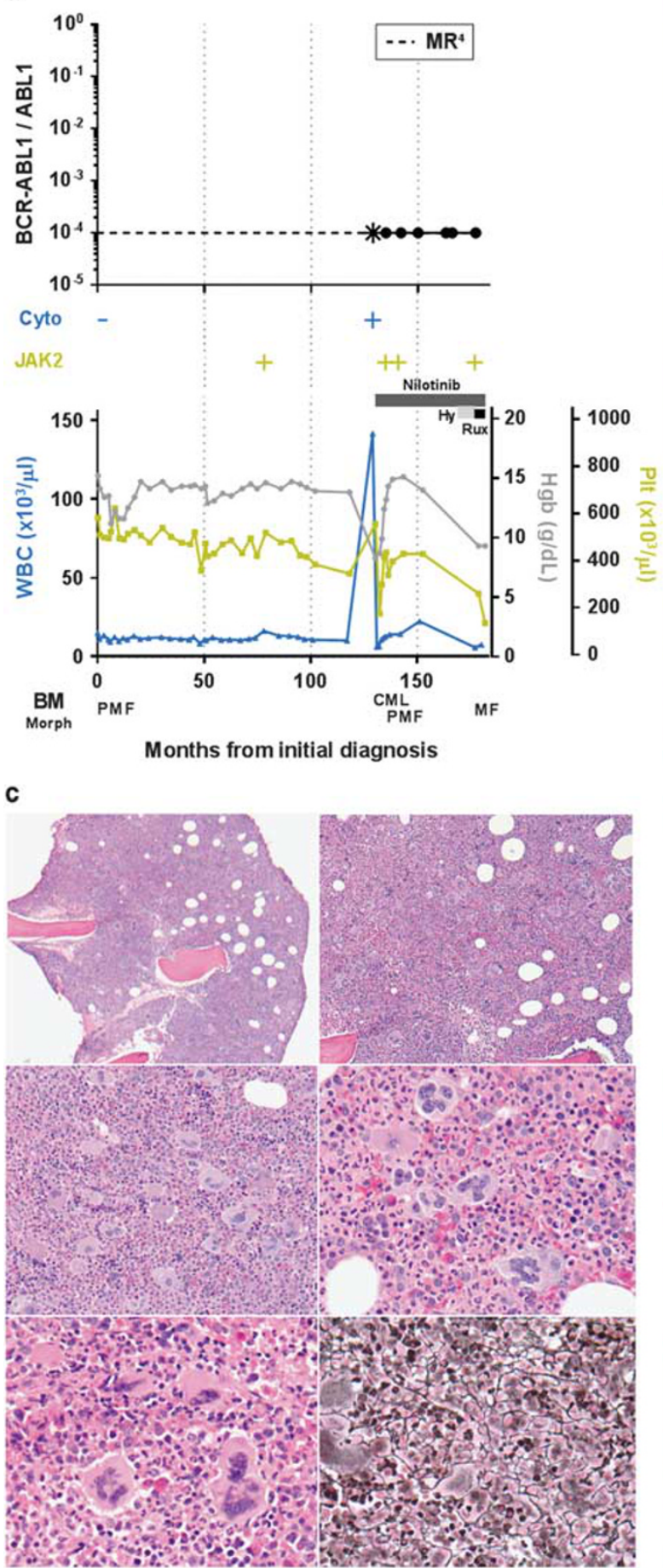

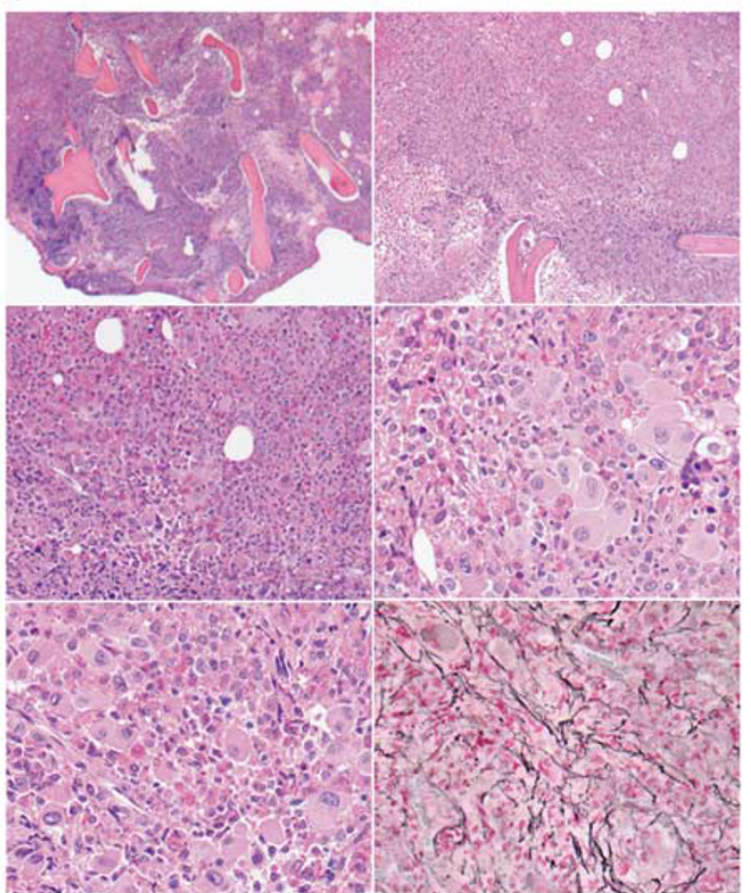

d

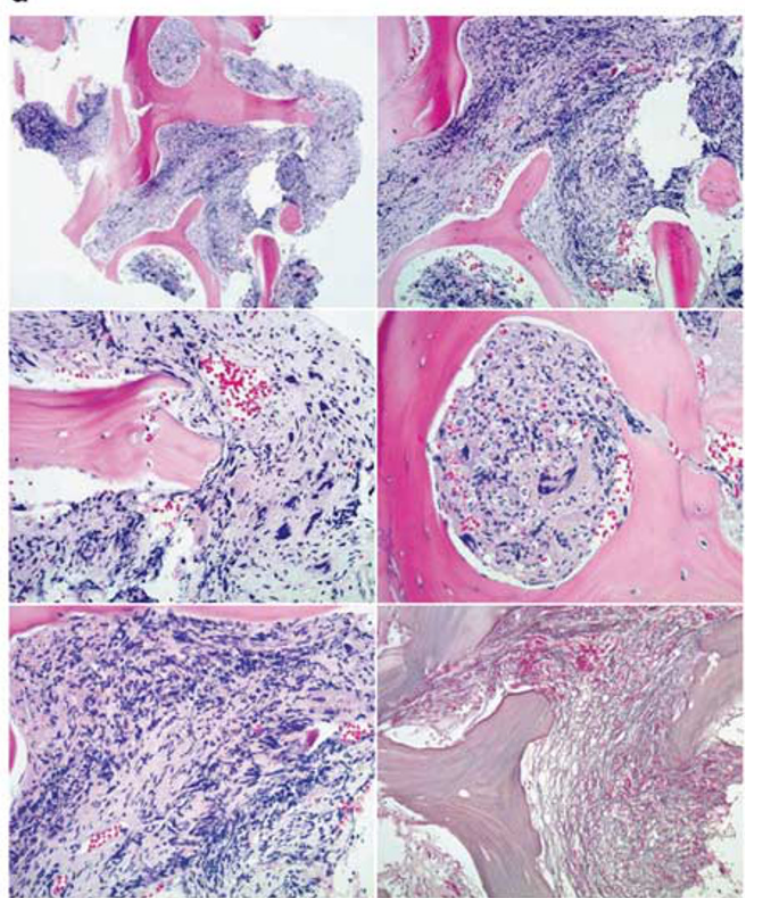

Figure 1 Patient 1, time course of laboratory and histopathologic features in a patient with longstanding JAK2 V617F+ primary myelofibrosis who subsequently acquired $B C R-A B L 1$. Temporary switch to chronic myeloid leukemia phenotype followed by tyrosine kinase inhibitor induced reversion to primary myelofibrosis. (a) Time course of $B C R-A B L 1$ transcript levels (log scale), cytogenetic t(9;22) results (Cyto), JAK2 V617F status, treatment, peripheral blood counts and bone marrow morphology, Hy = hydroxyurea, Rux = ruxolitinib, *the first quantitative $B C R-A B L 1$ assay performed after 3 months of tyrosine kinase inhibitor therapy revealed that molecular response ${ }^{4}$ had been attained. (b) Bone marrow core biopsy at identification of $B C R-A B L 1$ (month 129) showing predominant features of chronic myeloid leukemia. Hypercellular (top), increased M:E ratio, increased hypolobated megakaryocytes with clustering (middle, bottom left), mildly increased reticulin fibrosis, grade 1/3 (bottom right). (c) Bone marrow core biopsy after 6 months of tyrosine kinase inhibitor therapy (month 135) showing predominant features of primary myelofibrosis. Hypercellular (top), mildly increased large megakaryocytes with bulbous nuclei (middle, bottom left), increased reticulin fibrosis, grade 1-2/3 (bottom right). (d) Bone marrow core biopsy following tyrosine kinase inhibitor and hydroxyurea therapy (month 177) showing progression to fibrotic phase primary myelofibrosis. Focally hypercellular (top), increased hyperchromatic megakaryocytes (middle, bottom left), markedly increased reticulin fibrosis, grade $3 / 3$ (bottom right). 


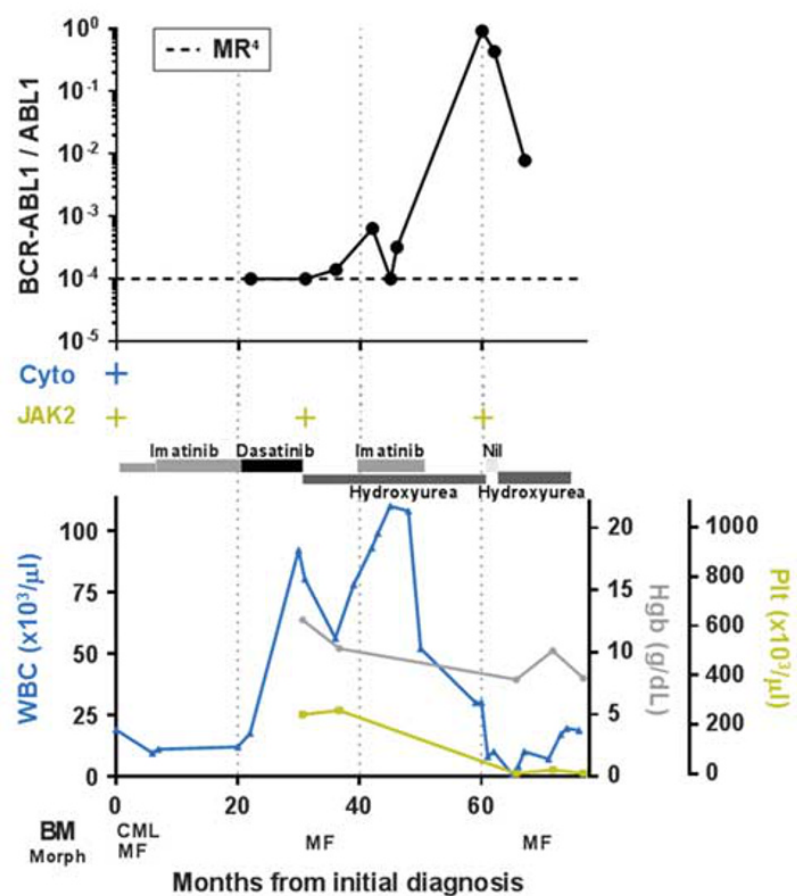

C

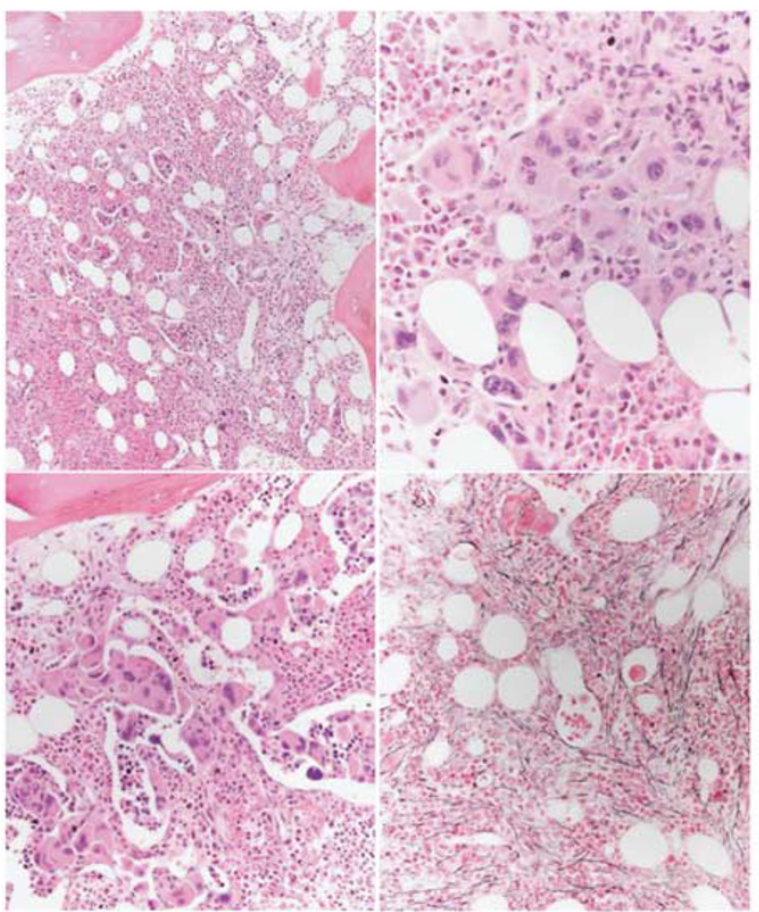

b

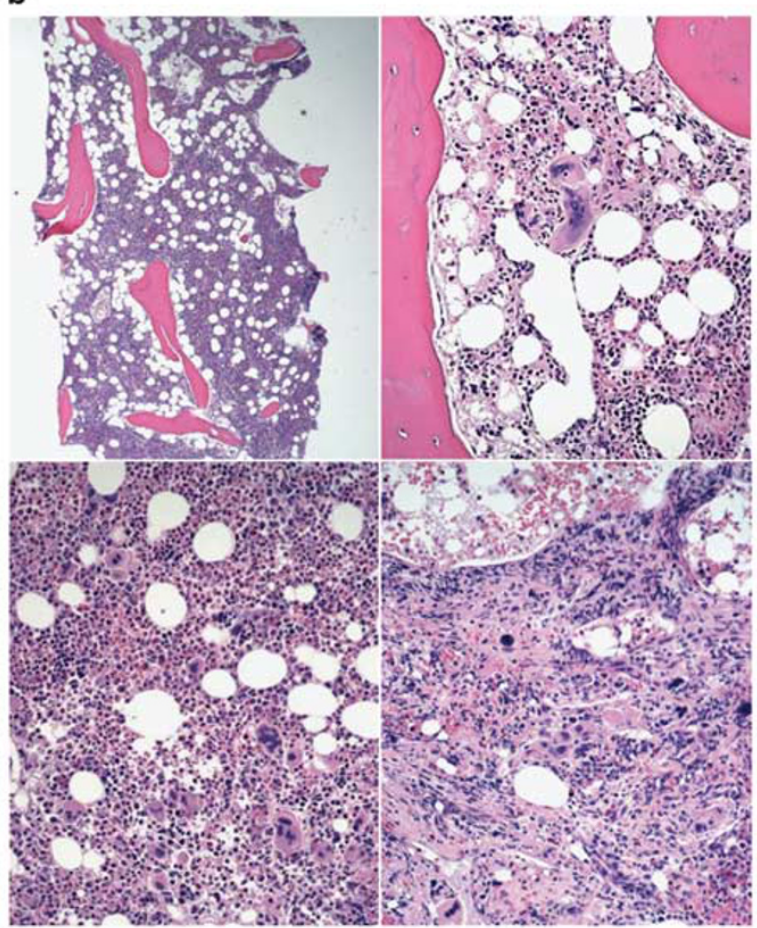

d

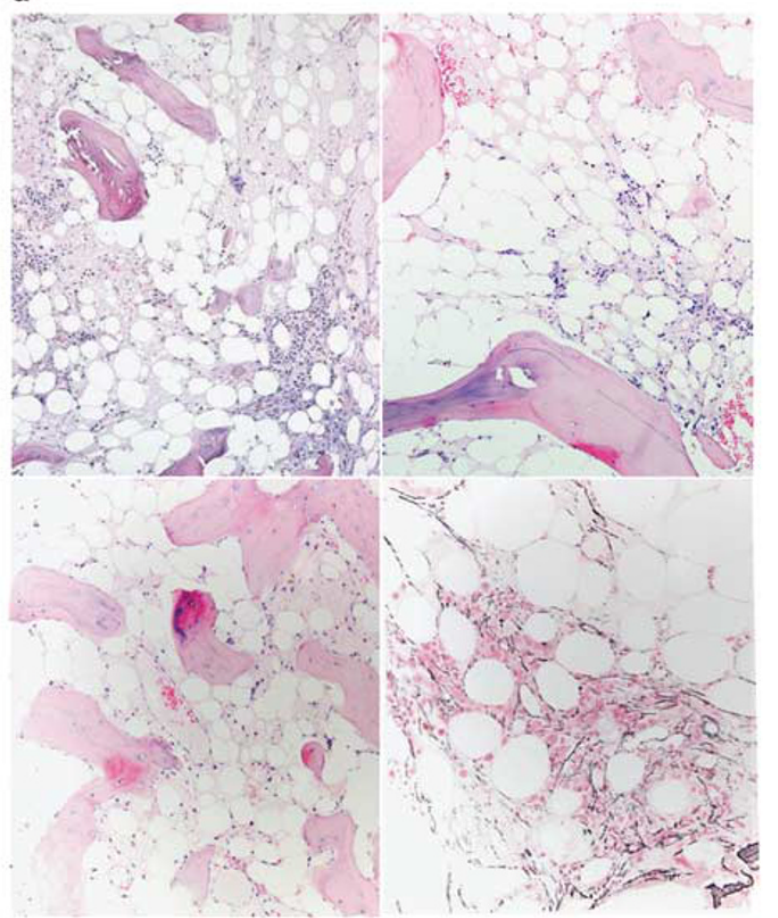

Figure 2 Patient 7, time course of laboratory and histopathologic features in a patient with simultaneously identified $B C R-A B L 1$ and $J A K 2$ V617F. Mixed morphologic features at both initial diagnosis and follow-up with progression to marrow failure. (a) Time course of $B C R-$ ABL1 transcript levels (log scale), cytogenetic t(9;22) results (Cyto), JAK2 V617F status, treatment, peripheral blood counts and bone marrow morphology, Nil = nilotinib. (b) Bone marrow core biopsy at initial diagnosis (month 0) showing features of chronic myeloid leukemia and myelofibrosis. Hypercellular (top left), mixed population of small hypolobated megakaryocytes and larger forms with atypical morphology (bulbous 'cloud-like' nuclei, hyperlobation) with some clustering (top right, lower). (c) Bone marrow core biopsy following tyrosine kinase inhibitor therapy showing predominant features of myelofibrosis (month 31). Hypercellular (top left), marked granulocytic hyperplasia, increased atypical megakaryocytes with variably bulbous 'cloud-like' morphology (top right), many intrasinusoidal megakaryocytes (bottom left), increased reticulin fibrosis, grade 2/3 (bottom right). (d) Bone marrow core biopsy following tyrosine kinase inhibitor and hydroxyurea therapy (month 65). Hypocellular ( 10\%) (top), osteosclerosis and residual reticulin fibrosis (bottom). 


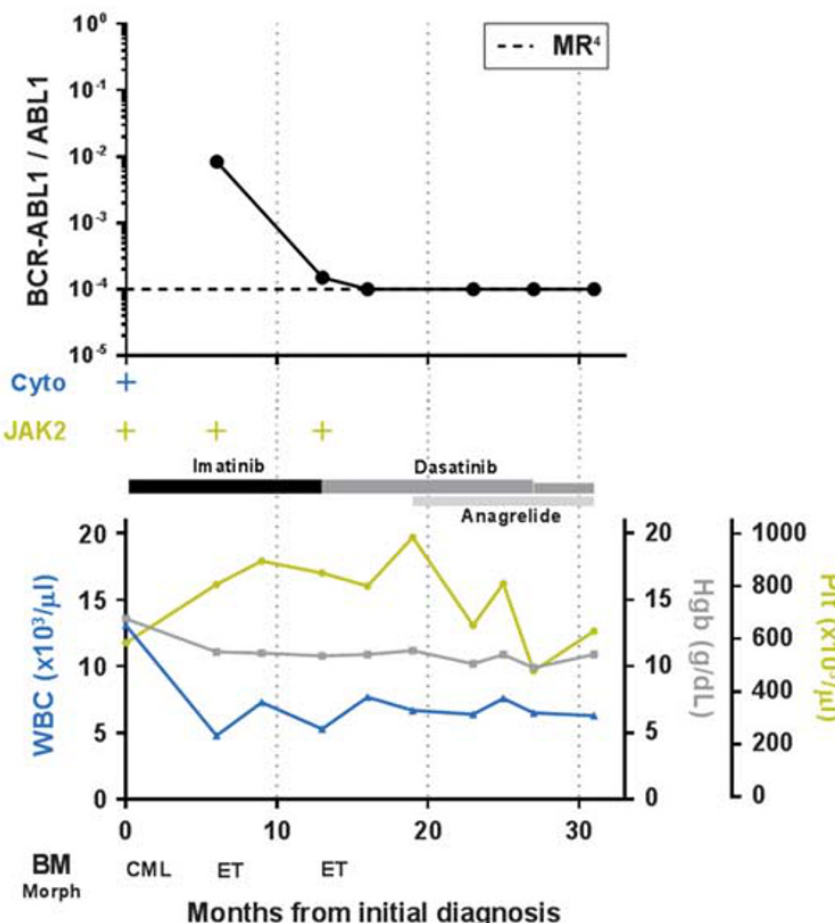

c

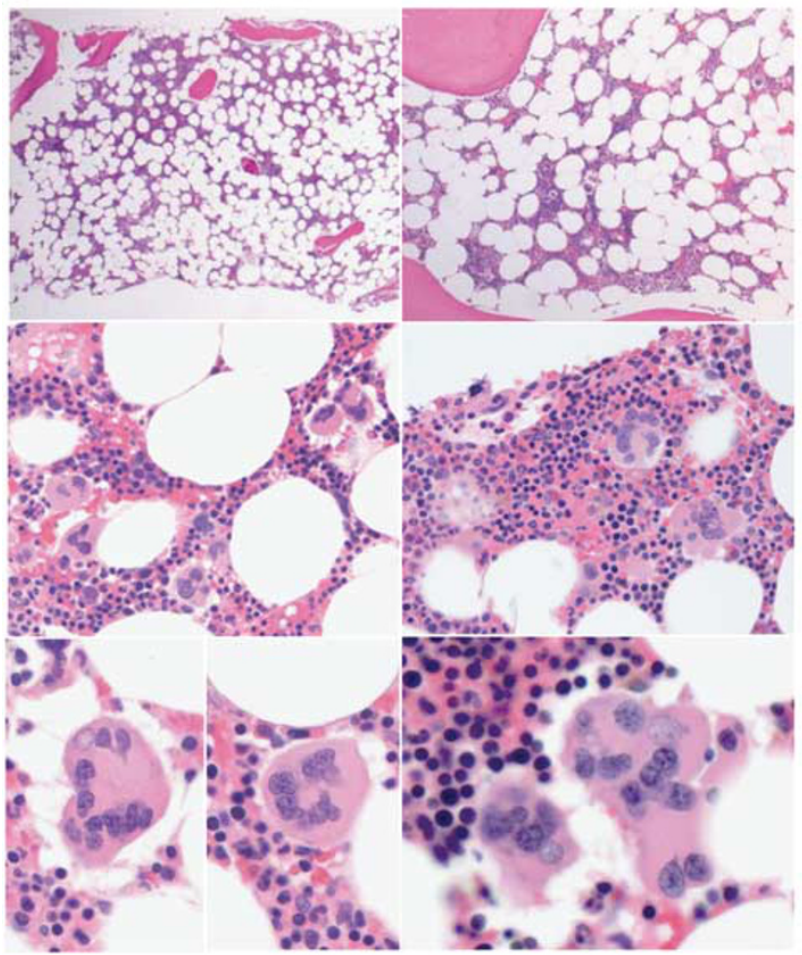

b

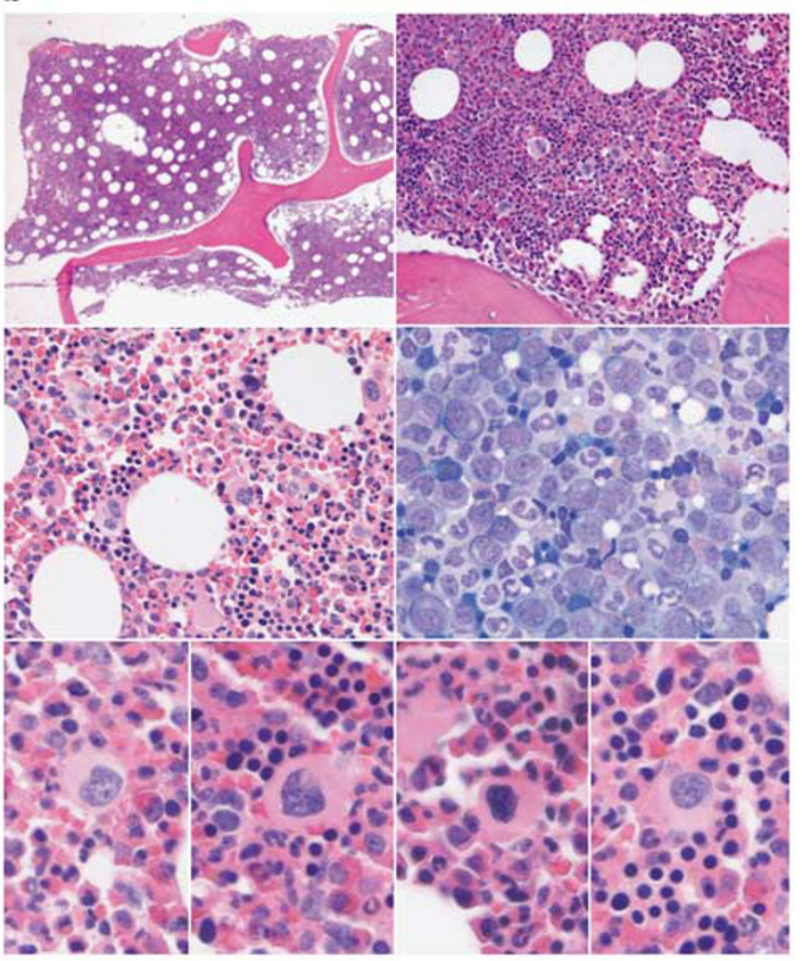

d

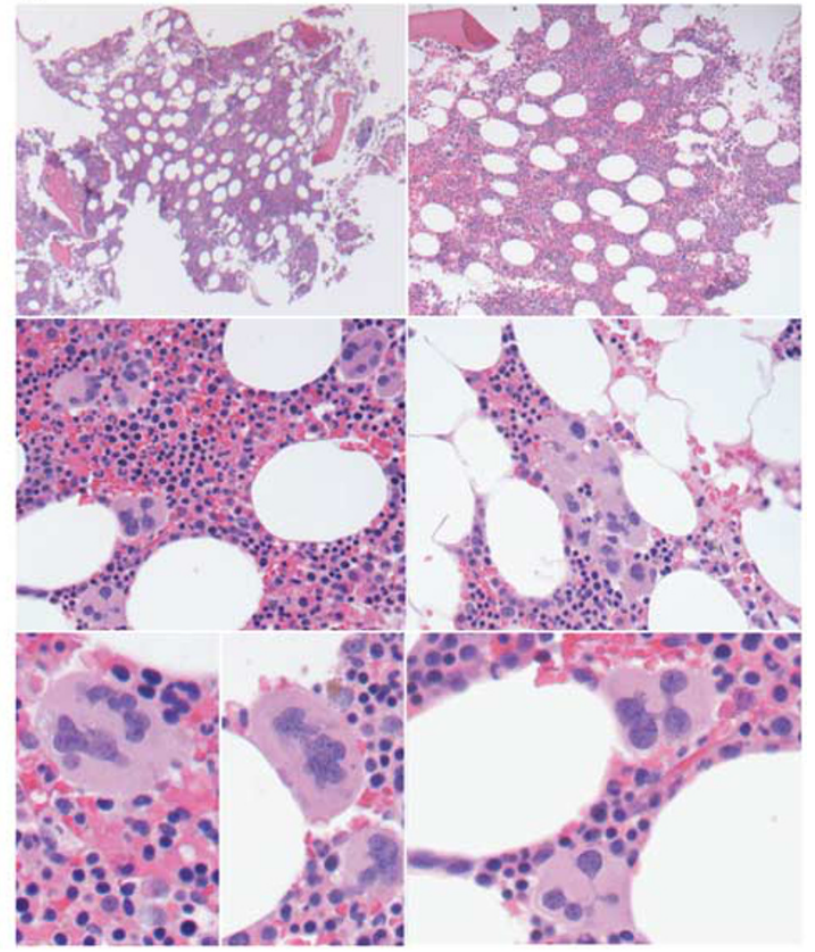

Figure 3 Patient 8, time course of laboratory and histopathologic features in a patient with simultaneously identified $B C R-A B L 1$ and $J A K 2$ V617F. Tyrosine kinase inhibitor therapy for $B C R-A B L 1$ unmasks an essential thrombocythemia phenotype. ${ }^{37}$ (a) Time course of $B C R-$ $A B L 1$ transcript levels (log scale), cytogenetic $\mathrm{t}(9 ; 22)$ results (Cyto), JAK2 V617F status, treatment, peripheral blood counts and bone marrow morphology. (b) Bone marrow core biopsy at initial diagnosis (month 0) showing predominant features of chronic myeloid leukemia. Hypercellular (top), elevated M:E ratio (middle ), small hypolobated megakaryocytes (bottom). (c, d) Bone marrow core biopsy after tyrosine kinase inhibitor therapy (month 6 and month 13, respectively) showing predominant features of essential thrombocythemia. Normocellular (c) to mildly hypercellular (d), hyperlobated 'staghorn' megakaryocytes with clustering (middle and bottom). 
a

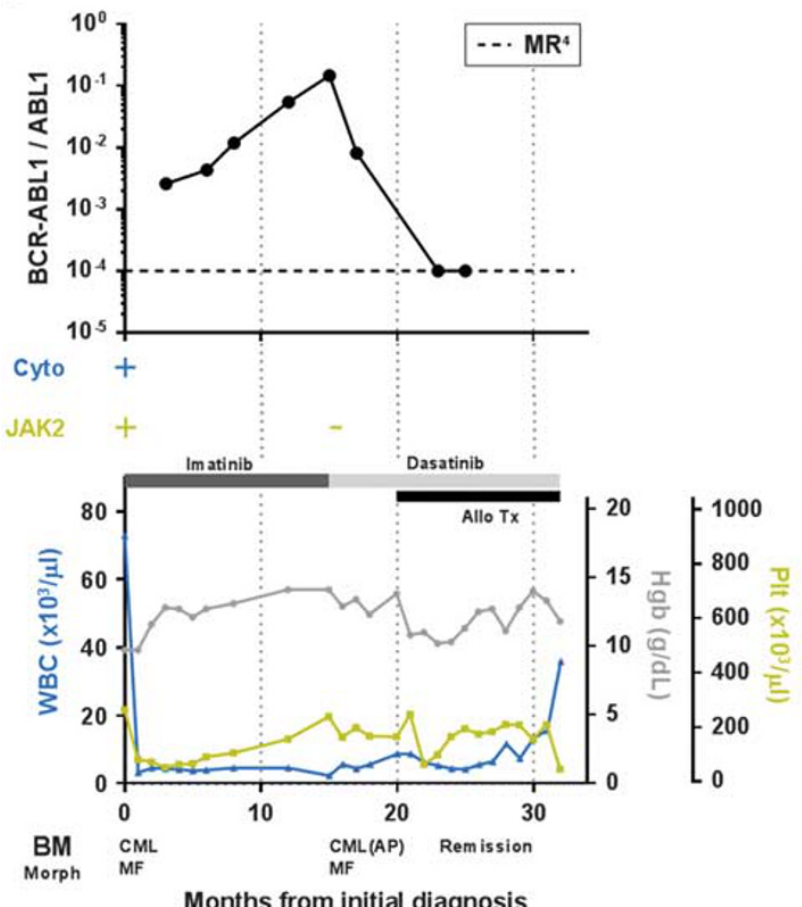

Months from initial diagnosis

C

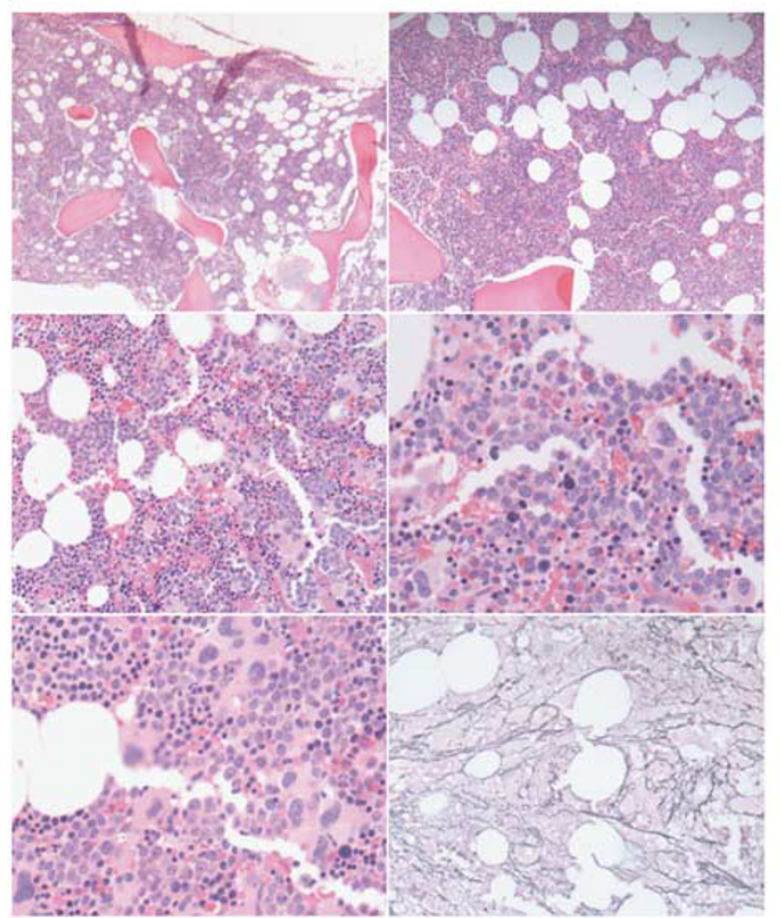

b

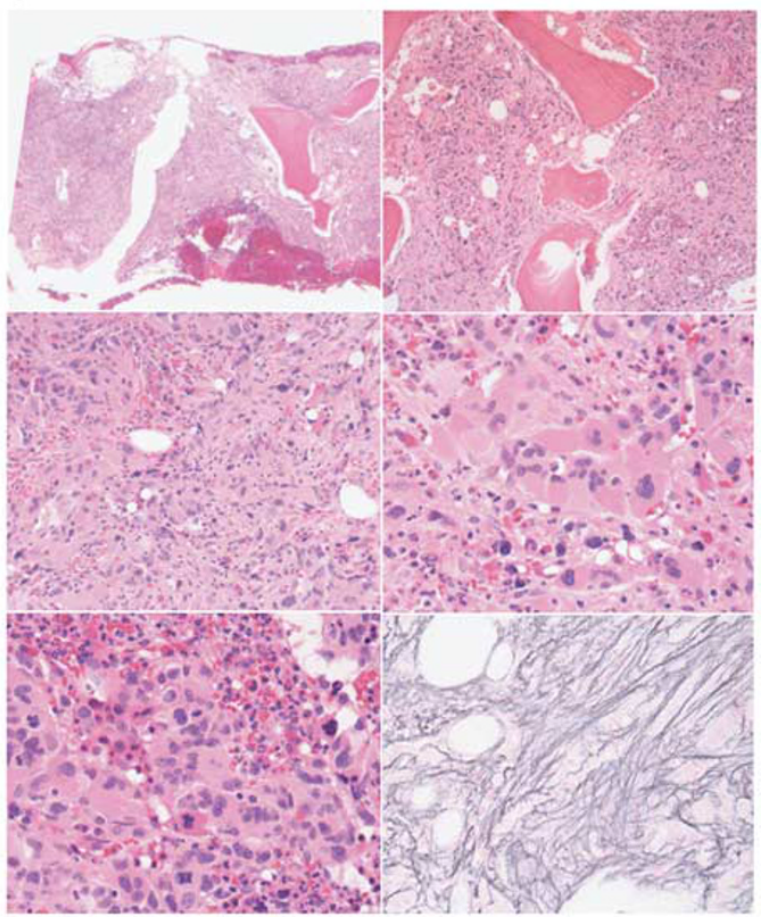

d

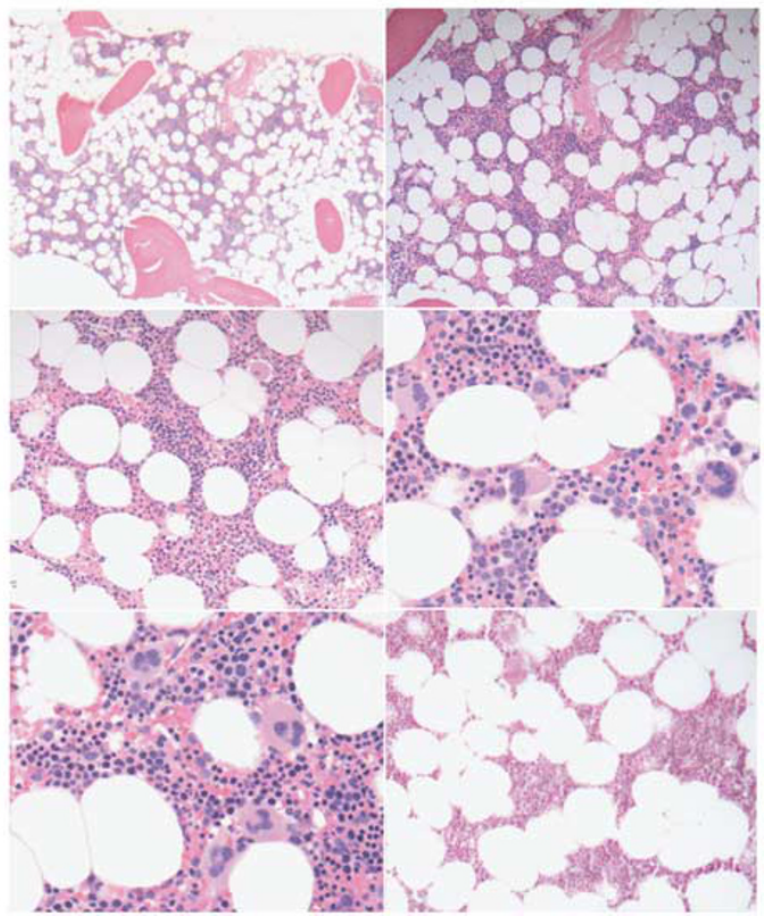

Figure 4 Patient 9, time course of laboratory and histopathologic features in a patient with simultaneously identified BCR-ABL1 and JAK2 V617F. Mixed histomorphologic features with progression to accelerated phase chronic myeloid leukemia followed by allogeneic transplant induced remission. (a) Time course of $B C R-A B L 1$ transcript levels (log scale), cytogenetic t(9;22) results (Cyto), JAK2 V617F status, treatment, peripheral blood counts and bone marrow morphology, Allo Tx = allogeneic transplant. (b) Bone marrow core biopsy at initial diagnosis (month 0) showing features of chronic myeloid leukemia and myelofibrosis. Hypercellular (top), markedly increased hypolobated megakaryocytes with clustering (middle, bottom left), increased reticulin fibrosis, grade $3 / 3$ (bottom right). (c) Bone marrow core biopsy after 15 months of tyrosine kinase inhibitor therapy (month 15) showing accelerated phase chronic myeloid leukemia. Hypercellular (top), increased myeloblasts (5-10\%) (middle), atypical hypolobated megakaryocytes (bottom left), decreased reticulin fibrosis, grade 2/3 (bottom right). (d). Bone marrow core biopsy following stem cell transplant (month 23). Normocellular (top), trilineage hematopoiesis, no morphologic evidence of $J A K 2+B C R-A B L 1+$ myeloproliferative neoplasm (middle, bottom left), grade $0 / 3$ reticulin fibrosis (bottom right). 
marrows showed hypercellularity, and four of five (patients 1, 2, 4 and 5) displayed granulocytic hyperplasia, whereas patient 3 showed panmyelosis. Megakaryocytic atypia was variably prominent with the most common morphology being small, hypolobated forms ('dwarf' megakaryocytes), though large atypical megakaryocytes were additionally present in the marrow of patient 4 . Patient 5 showed 10-15\% myeloblasts and left-shifted granulocytic hyperplasia, findings that were interpreted to represent chronic myeloid leukemia in accelerated phase. Other than the myelofibrosis and the single case with large atypical megakaryocytes, there were no morphologic findings that could be attributable to the presence mutant JAK2. Although morphologic features of chronic myeloid leukemia most often predominated, final interpretation generally acknowledged the dual contribution of both genetic lesions.

Laboratory and molecular response to treatment of JAK2+ BCR-ABL1+ myeloproliferative neoplasm. All patients started tyrosine kinase inhibitor therapy upon identification of $B C R-A B L 1$, and in some cases, therapy directed toward the $\mathrm{Ph}$-negative neoplasm was terminated. Response of the BCR-ABL1-harboring clones to tyrosine kinase inhibitor therapy varied. In patient 1, confirmed molecular response ${ }^{4}$ (quantitative molecular response showing a 4 log decrease in $B C R-A B L 1$ transcripts) was achieved and maintained (Figure 1), whereas in the remaining four cases, suboptimal molecular responses were noted. In two cases (patients 4 and 5), including the patient who presented with accelerated phase chronic myeloid leukemia, tyrosine kinase inhibitor therapy failed to achieve a single log reduction in $B C R-A B L 1$ transcripts in the short follow-up period (tested at 3 and 4 months, respectively) before death. Patients 2 and 3 showed molecular evidence of tyrosine kinase inhibitor failure with only a single log reduction at latest follow-up (tested at 18 and 25 months, respectively).

Assessment of the response of the JAK2+ harboring cells is complicated by less frequent testing and semiquantitative nature of the assay. Patients 1 and 5 had positive JAK2 studies following tyrosine kinase inhibitor treatment; the other three patients were not tested. Patient 1, who showed BCR-ABL1 molecular response $^{4}$, experienced an apparent increase in mutant JAK2 allele burden (initially interpreted to be monoallelic on a semiquantitative assay, subsequently found to have $78 \%$ mutated JAK2 alleles by next-generation sequencing; Figure 1). Patient 5, with accelerated phase chronic myeloid leukemia, had a JAK2 V617F allele burden of $<10 \%$ at identification of $B C R-A B L 1$, as well as 4 months later, a finding that likely reflects the relative dominance of the $B C R-A B L 1$-driven disease during that period of time.

All patients showed mild to moderate peripheral blood count abnormalities at latest follow-up variably involving all three myeloid lineages. Patient 1 showed an initial normalization of peripheral counts followed by progressive anemia and thrombocytopenia (Figure 1). Patients 4 and 5 never established complete normalization of blood counts in the limited follow-up period before death (at 4 and 6 months following identification of $B C R-A B L 1$, respectively). Leukocytosis, thrombocytopenia and anemia were the most common group-wide findings.

Bone marrow morphologic response to treatment of JAK2+ BCR-ABL1+ myeloproliferative neoplasm. Post-therapy bone marrow evaluation was only available for patient 1 . In this patient, who had a longstanding history of primary myelofibrosis, an initial morphologic response to tyrosine kinase inhibitor therapy was evident after 6 months of therapy, with a decrease in the granulocytic hyperplasia and left-shift, reverting the apparent phenotype from that of chronic myeloid leukemia back to primary myelofibrosis. Although molecular studies showed complete abrogation of $B C R-A B L 1$ transcripts, a subsequent bone marrow biopsy after 4 years of tyrosine kinase inhibitor therapy showed progressive myelofibrosis (Figure 1). Of the remaining four patients, patients 4 and 5 did not have posttherapy bone marrow biopsies because of disease progression and death, and patients 2 and 3 had incomplete follow-up.

Outcome. At latest documented follow-up, patients 1-3 in this group are alive. Patient 1 has complications of fibrotic stage myelofibrosis (progressive pancytopenia, splenomegaly and profound constitutional symptoms) warranting JAK inhibitor therapy (Figure 1). Patients 2 and 3 were clinically stable with limited follow-up. Two patients have died: patient 5 succumbed 4 months after diagnosis of chronic myeloid leukemia in accelerated phase (77 months after initial diagnosis of polycythemia vera) and patient 4 died 6 months after acquisition of $B C R-A B L 1$ (113 months following initial diagnosis of polycythemia vera) because of complications of progressive myelofibrosis.

\section{Group 2: BCR-ABL1 Detected First, JAK2 V617F Second (Patient 6)}

Laboratory findings and treatment during chronic myeloid leukemia disease phase. One of our 11 patients (patient 6) initially presented with BCR$A B L 1+$ chronic myeloid leukemia in chronic phase before the subsequent detection of JAK2 V617F, 109 months following initial diagnosis. Cytogenetics showed a 45-46,XX,del(3)(?),t(9;22)(q34;q11.2),-10 at diagnosis. After tyrosine kinase inhibitor therapy was initiated, molecular response ${ }^{3}$ was initially achieved, but persistently positive, with low-level $B C R-A B L 1$ transcripts detected up until the time that JAK2 V617F was identified (range $0.02-1.08 \%$ IS). 
Although this patient maintained essentially normal WBC counts, rising platelet counts (from $242 \times 10^{3} / \mu \mathrm{l}$ to $638 \times 10^{3} / \mu \mathrm{l}$ ) were noted during the 2 years preceding detection of JAK2 V617F.

Bone marrow histology during chronic myeloid leukemia disease phase. Before JAK2 V617F identification, this patient's bone marrow biopsies showed histologic features consistent with chronic myeloid leukemia, including granulocytic hyperplasia and left-shifted myeloid series. There were no overt morphologic features of Ph-negative myeloproliferative neoplasm.

Laboratory hematology findings at time of identification of JAK2 V617F. A CBC was notable for marked thrombocytosis (Plt $858 \times 10^{3} / \mu \mathrm{l}$ ) without leukocytosis or anemia (WBC $6.9 \times 10^{3} / \mu \mathrm{l}$, Hgb $12.1 \mathrm{~g} / \mathrm{dl}$ ). Ovalocytes and dacrocytes were noted on peripheral blood smear.

Genetic findings at time of identification of JAK2 V617F. Molecular studies showed a moderate response to tyrosine kinase inhibitor therapy at the time of JAK2 V617F identification: $B C R-A B L 1$ transcripts showed a $2.4 \log$ reduction from $100 \%$ IS. Cytogenetic analysis was negative for $t(9 ; 22)$, but interestingly showed a new karyotypic anomaly: 46, XX,add(17)(p12)[17]/46,XX[3]. The first JAK2 study performed on this patient, 109 weeks following their diagnosis of chronic myeloid leukemia, was qualitative only. This patient had never been tested for a JAK2 mutation during her earlier chronic myeloid leukemia disease phase.

Bone marrow histology at time of identification of $J A K 2$ V617F. Bone marrow biopsy performed at the time of JAK2 V617F identification showed a hypercellular marrow with increased numbers of morphologically atypical megakaryocytes that included hyperlobated, hypolobated and hyperchromatic forms. The marrow showed grade $2 / 3$ reticulin fibrosis. A diagnosis of myeloproliferative neoplasm, not otherwise specified was rendered here, acknowledging the challenges in arriving at a definitive classification in this setting.

Laboratory and molecular response to treatment of JAK2+ BCR-ABL1+ myeloproliferative neoplasm. Over the subsequent years, the patient was treated with first- and second-generation tyrosine kinase inhibitors but never received a JAK inhibitor. During the first 6 years of follow-up, white blood cell counts remained within normal limits. Platelet counts were initially elevated $\left(858 \times 10^{3} / \mu \mathrm{l}\right)$, but trended downward (to $139 \times 10^{3} / \mu \mathrm{l}$ ). BCR-ABL1 transcript levels remained persistently low positive (range $0.004-1.74 \%$ IS). Bone marrow cytogenetic studies showed persistence of the cytogenetic abnormality on the short arm of chromosome 17, though $\mathrm{t}(9: 22)$ remained negative. The only quantitative $J A K 2$ study revealed a mutant allele burden of $27.6 \% 4$ years after initial JAK2 V617F identification.

Bone marrow morphologic response to treatment of $J A K 2+$ BCR-ABL1+ myeloproliferative neoplasm. Follow-up bone marrow studies performed over the subsequent 3 years showed persistent hypercellularity, with a normal to mildly elevated M:E ratio. Megakaryocytes were increased and clustered. Reticulin fibrosis remained increased (grade 2/3). Blasts were not increased at the last bone marrow evaluation.

Outcome. The patient remains alive on therapy, although comorbidities, including development of medulloblastoma, have necessitated admission to a skilled nursing facility. At most recent followup, this patient shows leukocytosis $\left(18.0 \times 10^{3} / \mu \mathrm{l}\right)$, anemia $(10.1 \mathrm{~g} / \mathrm{dl})$ and thrombocytopenia $\left(114 \times 10^{3} / \mu \mathrm{l}\right)$.

\section{Group 3: BCR-ABL1 and JAK2 V617F Detected Simultaneously (Patients 7-11)}

Laboratory hematology findings at diagnosis of JAK2 $+B C R-A B L 1+$ myeloproliferative neoplasm. These patients presented with variable peripheral blood abnormalities. Patients 7, 8, 10 and 11 had moderately elevated WBC counts (mean $15.1 \times 10^{3} / \mu \mathrm{l}$, range $12.8-18.5 \times 10^{3} / \mu \mathrm{l}$ ) (Figures 2 and 3 ), whereas patient 9 presented with marked leukocytosis $\left(72.9 \times 10^{3} / \mu \mathrm{l}\right)$ (Figure 4). Patient 9 was anemic $(9.7 \mathrm{~g} / \mathrm{dl})$, whereas the other four had mostly normal hemoglobin levels (mean $13.0 \mathrm{~g} / \mathrm{dl}$, range 11.7$13.6 \mathrm{~g} / \mathrm{dl}$ ). Patient 8 showed thrombocytosis $\left(670 \times 10^{3} / \mu \mathrm{l}\right)$, whereas the other four had platelet counts less than $450 \times 10^{3} / \mu \mathrm{l}$ (mean $360 \times 10^{3} / \mu \mathrm{l}$, range $\left.268-432 \times 10^{3} / \mu \mathrm{l}\right)$.

Genetic findings at diagnosis of JAK2+ BCR-ABL1+ myeloproliferative neoplasm. Both $B C R-A B L 1$ and $J A K 2$ alterations were identified at initial diagnosis. Patients 7, 8, 9 and 10 displayed high levels of $t(9 ; 22)$ and/or BCR-ABL1-positive cells, with metaphase analysis showing a mean of $83 \%$ positive cells (range 60-100\%). In patient 11, cytogenetic analysis revealed 46,XX,t(9;22)(q34;q11.2)[2]/46,XX[19] and only $5 \% B C R-A B L 1$ positivity by FISH; RT-PCR in this patient showed the e1a2 $B C R-A B L 1$ transcript only. Measurements of JAK2 levels were available for patients 8 and 10, and revealed a mutant allele fraction of $<20 \%$.

Bone marrow histology at diagnosis of JAK2+ BCRABL1+ myeloproliferative neoplasm. Bone marrow findings in this group were heterogeneous with relatively few consistent group-wide findings. All marrows were hypercellular and $\mathrm{M}: \mathrm{E}$ ratio was mildly increased in each case (mean 3:8 to 1, range 
3.4-5 to 1). Megakaryocytes showed atypical morphology and localization, though the atypical features varied by case. Patient 7 showed some small hypolobated megakaryocytes, as well as some with bulbous or cloud-like nuclei with moderate loose clustering and grade $2 / 3$ reticulin fibrosis (Figure 2 ). In patients 8 and 11 , megakaryocytes showed predominantly prototypic chronic myeloid leukemia morphology (Figure 3). Conversely, patient 9 showed marked megakaryocytic hyperplasia (accounting for $\sim 35 \%$ of total cellularity) with large clusters of hypolobated and hyperchromatic forms (Figure 4). Patient 9 showed 3/3 reticulin fibrosis with osteosclerosis, patients 7,10 and 11 showed grade $2 / 3$ fibrosis, and patient 8 showed grade $0 / 3$. Overall, patient 8 showed features most consistent with chronic phase chronic myeloid leukemia (Figure 3), whereas the other four had nonspecific myeloproliferative features (Figures 2 and 4).

Laboratory and molecular response to treatment of JAK2+ BCR-ABL1+ myeloproliferative neoplasm. All patients started tyrosine kinase inhibitor therapy upon diagnosis; no additional therapy for the Phnegative myeloproliferative neoplasm was started at that time. Patient 7 initially showed $>3$ log reduction in $B C R-A B L 1$ transcripts during tyrosine kinase inhibitor therapy; however, $B C R-A B L 1$ transcripts increased when tyrosine kinase inhibitor therapy was temporarily withdrawn (Figure 2). Patient 8 achieved and maintained molecular response ${ }^{4}$ (Figure 3). Patient 9 failed both first- and secondgeneration tyrosine kinase inhibitors before advancing to an allogeneic stem cell transplant. Following transplant, $B C R-A B L 1$ transcripts became undetectable (Figure 4). Patient 10 showed molecular evidence of disease progression (with BCR-ABL1 now showing a $<1$ log reduction) following acquisition of the imatinib-resistant p.E255K and p.T315I $A B L 1$ mutations. Patient 11, who had only low-level $B C R-A B L 1$ disease burden at diagnosis $(5 \%$ BCR$A B L 1$ positivity by FISH), showed relatively stable low-level $B C R-A B L 1$ transcripts equivalent to a $2 \log$ 'reduction' from the standardized baseline throughout treatment.

Patients 7, 8 and 10 subsequently received therapy more specifically targeting the Ph-negative myeloproliferative neoplasm and follow-up JAK2 studies were performed for patients 7, 8, 9 and 11 . Patients 7, 8 and 11 remained positive for JAK2 V617F, consistent with the present dearth of treatments that effectively target JAK2 V617F clones. Mutated JAK2 allele percentage remained relatively low (7-8\%) over the course of treatment for patient 7 (Figure 2). Following tyrosine kinase inhibitor therapy but before initiation of anagrelide, semiquantitative studies for patient 8 showed an apparent increase in the percentage of mutant JAK2 alleles (from $<10$ to $>25 \%$ ), with a corresponding 2.4- $\log$ reduction in $B C R-A B L 1$ transcripts; no JAK2 studies were performed after anagrelide therapy (Figure 3).
Surprisingly, follow-up on patient 9, who did not receive treatment specific for $\mathrm{Ph}$-negative myeloproliferative neoplasm, demonstrated a disappearance of the JAK2 V617F clone. However, this study was performed at disease progression to accelerated phase chronic myeloid leukemia with a tyrosine kinase inhibitor-resistant $B C R-A B L 1$ clone, suggesting preferential expansion of an independent clone (Figure 4).

Despite therapeutic intervention, patient 7 developed progressive anemia and thrombocytopenia with moderate leukocytosis before death (Figure 2). Following tyrosine kinase inhibitor therapy, patient 8 achieved and maintained normalized white counts $\left(13.1-4.8 \times 10^{3} / \mu l\right)$ but showed increased thrombocytosis $\left(670-809 \times 10^{3} / \mu \mathrm{l}\right)$. Platelet levels remained elevated until anagrelide therapy was initiated (Figure 3). Patient 9 showed a WBC response following tyrosine kinase inhibitor therapy (72.9$3.2 \times 10^{3} / \mu \mathrm{l}$ ), which was sustained for over 2 years before the development of leukocytosis $\left(35.9 \times 10^{3}\right.$ / $\mu \mathrm{l}$ ) and soon after died (Figure 4). Patient 10 showed a transient improvement of hematologic parameters at last evaluation (WBC $15.2 \times 10^{3} / \mu \mathrm{l}$, Hgb $9.4 \mathrm{~g} / \mathrm{dl}$, Plt $189 \times 10^{3} / \mu \mathrm{l}$ ) before his discharge from the hospital and subsequent death from disease complications. Patient 11 maintained low-level leukocytosis throughout the follow-up period of 17 months (range 12.8-16.3 $\times 10^{3} / \mu \mathrm{l}$ ) with an essentially normal hemoglobin (range 12.5-13.6 g/dl) and high normal platelet count (range $409-440 \times 10^{3} / \mu \mathrm{l}$ ).

Bone marrow morphologic response to treatment of JAK2+ BCR-ABL1+ myeloproliferative neoplasm. All patients had post-therapy bone marrow evaluation with a wide array of morphologic responses. After many modifications in therapy over 5 years, a bone marrow biopsy performed on patient 7 was hypocellular $(\sim 10 \%)$ with residual myelofibrosis and osteosclerosis (Figure 2). Patient 8, whose initial bone marrow revealed morphologic features consistent with chronic myeloid leukemia, showed normalization of $\mathrm{M}: \mathrm{E}$ ratio and a predominance of hyperlobated 'staghorn' megakaryocytes with the disappearance of the 'dwarf' megakaryocytes after 6 and 13 months of tyrosine kinase inhibitor therapy. Therapy had essentially unmasked an essential thrombocythemia phenotype (Figure 3). ${ }^{37}$ Patient 9, whose initial marrow revealed features of both chronic myeloid leukemia and myelofibrosis and grade $3 / 3$ myelofibrosis, showed progression to an apparent accelerated phase tyrosine kinase inhibitorresistant chronic myeloid leukemia with persistent (but mildly decreased) myelofibrosis after 15 months of therapy (Figure 4). Following an allogeneic stem cell transplant, the marrow showed no residual evidence of a myeloproliferative neoplasm (Figure 4). Patient 10, whose follow-up study consisted of a bone marrow aspirate smear only, showed progression to blast phase chronic myeloid leukemia (51\% myeloblasts). Patient 11 showed no significant 
changes in bone marrow morphology after 4 months of tyrosine kinase inhibitor therapy.

Outcome. At most recent follow-up, patients 8 and 11 are alive with clinically stable disease. Patient 7 died 76 months after initial diagnosis secondary to complications of pneumonia, patient 10 died from complications of disease following progression to blast phase chronic myeloid leukemia and patient 9 died 32 months following diagnosis of his myeloproliferative neoplasm because of complications of bone marrow transplant.

\section{Discussion}

We identified 11 patients with co-occurring BCR$A B L 1$ and JAK2 V617F mutations and provide a comprehensive analysis of their clinical, hematologic, pathological and genetic features. This study reflects the most detailed report to date of such cases. Although clinical courses varied, in the absence of tyrosine kinase inhibitor therapy, patients generally demonstrated clinicopathologic features of chronic myeloid leukemia, suggesting that $B C R-A B L 1$ has comparatively dominant transforming potential in this setting. Many patients showed progression to myelofibrosis, raising the possibility the two mutant tyrosine kinases may accelerate disease progression. Our study highlights the importance of the recognition of this scenario to prevent inappropriate diagnosis and management.

\section{Frequency of Occurrence}

Our review of 1570 patients with suspected myeloproliferative neoplasm who underwent concurrent testing for both $B C R-A B L 1$ and JAK2 V617F identified six $(0.4 \%)$ who tested positive for both. An additional five cases were identified from clinical records. Two previous studies have provided estimates for the frequency of $B C R-A B L 1+J A K 2+$ myeloproliferative neoplasms, though their selected cohorts differ from our own. One reported a frequency of $0.2 \%$, a value that reflects a $B C R-$ $A B L 1+J A K 2+$ cohort (23 patients) among all patients (10 875) who were diagnosed with a myeloproliferative neoplasm (9134 JAK2 V617F+, 1487 BCR-ABL1 + and $254 \mathrm{MPL+}){ }^{38}$ Conversely, another group reported a frequency of $2.5 \%(8 / 314)$, a value generated by testing 314 patients with $B C R-A B L+$ chronic myeloid leukemia for JAK2 V617F from three centers in Italy. ${ }^{33}$ The disparity in these three reported frequencies likely reflects ascertainment bias as a consequence of the differences in the study design, as well as variance in testing practices between institutions and countries. Our study population is the broadest: all patients with a clinical suspicion of a myeloproliferative neoplasm who were concurrently tested for $B C R-A B L 1$ and $J A K 2$ $\mathrm{V} 617 \mathrm{~F}$, either at presentation or during follow-up.
Using this population, we establish a frequency of $J A K 2+B C R-A B L 1+$ myeloproliferative neoplasm, which is most clinically relevant during the initial phase of workup, given that it includes both patients who ultimately test positive, as well as those who ultimately test negative for both $B C R-A B L 1$ and $J A K 2$ V617F. The other study populations are narrowerthey evaluated only patients with prior myeloproliferative neoplasm diagnoses. Those selected populations (any patient with a mutation-positive myeloproliferative neoplasm or any patient with prior diagnosis of $B C R-A B L 1+$ chronic myeloid leukemia) more specifically assess the likelihood of finding an additional genetic alteration among those patients who already have one documented. Finally, it is clear that clinical testing practices affect these calculated frequencies, which likely vary widely between countries, institutions and even clinicians. The factors, which may prompt a clinician to test for both $B C R-A B L 1$ and $J A K 2 \mathrm{~V} 617 \mathrm{~F}$ at initial workup, rather than one or the other, may be influenced by clinical parameters, among others factors. Similarly, the clinical and/or laboratory findings, which prompt additional testing in a patient with a prior myeloproliferative neoplasm diagnosis are largely dependent on clinician initiative.

The striking difference in the percentage of patients who tested positive for $B C R-A B L 1$ among those who were tested for $B C R-A B L 1$ only $(38.9 \%)$ and those that were tested for both $B C R-A B L 1$ and JAK2 V617F (6.7\%) in our study may be due to a number of interrelated factors. As the hematologic features of chronic myeloid leukemia are more readily recognized by the ordering physician, a single $B C R-A B L 1$ assay but not a JAK2 assay is likely to be requested in this setting. By contrast, patients with a suspected JAK2 V617F-positive, $B C R-A B L 1$-negative myeloproliferative neoplasms often require a negative $B C R-A B L 1$ assay in order to fulfill WHO diagnostic criteria.

\section{Order of Mutation Identification}

Six of the 11 patients in our study were noted to apparently acquire the second mutation sequentially. Of these, five were positive for JAK2 V617F and negative for $B C R-A B L 1$ initially, with the subsequent acquisition of $B C R-A B L 1$, whereas the other was positive for $B C R-A B L 1$ initially, with $J A K 2$ V617F only detected subsequently, noting that this patient was not tested for a JAK2 V617F initially. These differences are not altogether surprising as a patient with a suspicion of a myeloproliferative neoplasm other than chronic myeloid leukemia is more likely to be tested for both (to seek the presence of a JAK2 V617F and absence of BCR-ABL1), whereas one with a suspicion for chronic myeloid leukemia is more likely to be tested for $B C R-A B L 1$ only at the time of presentation. 


\section{Clonal Composition}

Numerous prior reports have questioned the clonal composition of myeloproliferative neoplasms harboring both BCR-ABL1 and JAK2 V617F. Some studies have postulated that the two aberrations exist in the same clone or emerging subclones, ${ }^{4,7,9,16,35,36}$ whereas others have argued for the presence of two independently coexisting neoplasms (ie, 'composite tumor'). becoming increasingly clear from prior studies that each of these proposed theories is possible, that is, $B C R-A B L 1$ and $J A K 2$ V617F can exist in completely independent clones or the same clone, but with the majority of cases likely reflecting the presence of unrelated, independent clones.

We believe that our clinical data support this emerging consensus of the presence of a composite myeloproliferative neoplasm. Patient 8 (Figure 3), who presented with simultaneous detection of $B C R-A B L 1$ and $J A K 2 \mathrm{~V} 617 \mathrm{~F}$, showed initial clinical and morphologic features of chronic myeloid leukemia before tyrosine kinase inhibitor therapy. After tyrosine kinase inhibitor therapy effectively decreased $B C R-A B L 1$ transcripts and normalized WBC count, JAK2 allele burden and platelet counts increased and subsequent bone marrow histomorphology showed features of essential thrombocythemia. Similarly, patient 1 (Figure 1), who had a longstanding history of clinically and hematologically stable primary myelofibrosis, experienced a sudden unexplained leukocytosis prompting additional workup, which identified $B C R-$ $A B L 1$. At the time of $B C R-A B L 1$ identification, bone marrow histology showed features of chronic myeloid leukemia. FISH and cytogenetic studies pointed toward substantial BCR-ABL1 disease burden. Subsequent tyrosine kinase inhibitor therapy eliminated all hematologic and molecular genetic evidence of $B C R-$ ABL1-driven disease within 3 months, and bone marrow morphology reverted to that of primary myelofibrosis. In both of these patients, the response to tyrosine kinase inhibitor therapy argues for the presence of two distinct clones.

\section{Relative Dominance of Mutation}

Given the coexistence of two driver mutations in this patient population, it is important to understand the relative contribution of $B C R-A B L 1$ and mutant JAK2 in producing the clinicopatholgic phenotype. Many have postulated that the BCR-ABL1 tyrosine kinase is a stronger driver of cellular proliferation and may more effectively influence phenotype. ${ }^{13,16,26,33}$ JAK2 V617F, it follows, would have a smaller role in shaping the hematologic and morphologic phenotype. Within our cohort, a few key findings allow us to deduce the relative role of these two drivers. Among our patients with initially diagnosed JAK2+ myeloproliferative neoplasm, most of whom were under treatment, we noted marked left-shifted leukocytosis at the time of emergence of $B C R-A B L 1$.
Concurrently, bone marrow histology often showed morphologic features of chronic myeloid leukemia. These morphologic and hematologic findings were substantiated by the cytogenetic observation that $\mathrm{t}(9 ; 22)$ was present in nearly all cells. Simultaneously, JAK2 V617F was generally present in only a minor subset of cells, as exemplified by patient 5 . These findings suggest that BCR-ABL1 has dominant transforming potential in the setting of diminished mutationally activated JAK2. We also noted, in a subset of patients, that tyrosine kinase inhibitor therapy unmasked a Ph-negative myeloproliferative neoplasm phenotype. This observation suggests that essential clearance of the dominant BCR-ABL1 clone permits the weaker JAK2 driver to exert its effect. Prior reports have noted similar clinical courses. ${ }^{3,27,30,33}$

\section{Histologic Features Suggesting the Presence of Concurrent BCR-ABL1 and JAK2 V617F}

We sought to identify histologic features that might hint at the presence of multiple underlying genetic aberrations. Given the heterogeneous and often overlapping histologic features of myeloproliferative neoplasms, this presented a unique challenge. Although there are no specific features that will decisively point to coexistent mutations, a few findings should raise the index of suspicion. Cases that exhibit mixed bone marrow cytologic features (eg, both 'dwarf' and 'cloud-like' megakaryocytes) (Figure 2) or that show unexpected changes bone marrow histomorphology (eg, marked granulocytic hyperplasia and hypolobated megakaryocytes in a patient with known primary myelofibrosis) (Figure 1) should prompt consideration of the possible coexistence of $B C R-A B L 1$ and $J A K 2 \mathrm{~V} 617 \mathrm{~F}$.

\section{Laboratory Features Suggesting the Presence of Concurrent BCR-ABL1 and JAK2 V617F}

Similarly, we sought to identify molecular and laboratory features, which suggest the presence of coexistent mutations. Longitudinal molecular studies have an important role in monitoring disease progression and response to treatment in patients with myeloproliferative neoplasms, particularly those with chronic myeloid leukemia and we noted a few specific scenarios where molecular markers of disease burden and hematologic parameters were incongruent. In one patient with a history of chronic myeloid leukemia who subsequently acquired JAK2 V617F, tyrosine kinase inhibitor therapy had achieved a $>3 \log$ reduction in $B C R-A B L 1$ transcripts. Despite this apparent therapeutic success, platelet counts unexpectedly rose, a finding that ultimately led to the appropriate identification of JAK2 V617F. JAK2 mutant allele burden is less often used as a marker for disease status in Ph-negative 
myeloproliferative neoplasms and was not tested with sufficient frequency to reliably identify unexpected disease progression. However, in both patient 1 and patient 8 , while treatment with tyrosine kinase inhibitor effectively diminished $B C R-A B L 1$ transcripts, a concurrent apparent rise in JAK2 V617F allele burden was noted.

\section{Is the Location of the BCR Breakpoint Relevant?}

Although our numbers are low, we noted an unexpectedly high fraction of patients (3 of 11) with an e1 breakpoint in $B C R$, raising the question of the role of the p190 oncoprotein in this subset of patients. In vitro studies suggest the p190 protein has a fivefold increase in tyrosine kinase activity over p210, which may explain its increased association with acute rather than chronic leukemia ${ }^{39,40}$ though no difference in outcome has been identified in the setting of B-lymphoblastic leukemias with p190 vs p210. ${ }^{41}$ Additional studies have reported a monocytosis in a subset of chronic myeloid leukemia patients with e1a2 translocation. ${ }^{41,42}$ Among our three patients with p190, two died within 6 months of $B C R-A B L 1$ identification. One patient developed accelerated phase chronic myeloid leukemia, the other showed progressive myelofibrosis. The third patient remains clinically well at last follow-up. None of these three patients showed sustained monocytosis.

\section{Disease Progression}

It is worth noting that 7 of our 11 patients progressed to myelofibrosis, raising the possibility that these patients are more prone to progression. This finding also supports a concept that these cases exist within the more genetically complex end of the spectrum seen in myeloproliferative neoplasms. Although polycythemia vera, essential thrombocythemia and to a lesser degree chronic myeloid leukemia have a propensity to develop fibrosis, it seems reasonable that two mutant tyrosine kinases might act in concert to accelerate fibrosis. In those cases where both lesions had been identified, patients often received a tyrosine kinase inhibitor only. Although tyrosine kinase inhibitors are very effective for chronic myeloid leukemia, no similarly active tyrosine kinase inhibitor selectively targets JAK2 V617F. Thus, although one component of the patient's disease may be adequately treated, the second genetic alteration may not be. In our cohort, patient 1 (Figure 1) progressed to myelofibrosis despite a $>4.5 \log$ reduction in $B C R-A B L 1$-driven disease, indicating the dominant role that the mutant JAK2 had in development of the myelofibrosis. These findings are supported by similar reports in a subset of $B C R-A B L 1+J A K 2+$ patients. ${ }^{16,17}$

In summary, this is, to our knowledge the largest reported study comprehensively detailing clinicopathologic features evident when $B C R-A B L 1$ and JAK2 V617F co-occur. In some cases, features of an undiagnosed concurrent myeloproliferative neoplasm only manifest following treatment of the dominant myeloproliferative neoplasm. Although uncommon, it is important to be aware of this potentially confounding genetic combination, as these hematologic features may be misinterpreted to reflect resistance to therapy or disease progression, considerations that could lead to inappropriate management.

\section{Acknowledgments}

We thank Cordelia Sever MD, and Fan Yang MD, $\mathrm{PhD}$, for contributing bone marrow histology images, and Mohammad Vasef, MD, for performing additional molecular testing, for patient 7 .

\section{Disclosure/conflict of interest}

The authors declare no conflict of interest.

\section{References}

1 Swerdlow SH, Campo E, Harris NL, et al. WHO classification of tumours of haematopoietic and lymphoid tissues. World Health Organization Classification of Tumours. Chapter 2, Myeloproliferative Neoplasms; International Agency for Research on Cancer: Lyon, France. 2008;29-60.

2 Arber DA, Orazi A, Hasserjian R, et al. The 2016 revision to the World Health Organization classification of myeloid neoplasms and acute leukemia. Blood 2016;127:2391-2405.

3 Bee PC, Gan GG, Nadarajan VS, et al. A man with concomitant polycythaemia vera and chronic myeloid leukemia: the dynamics of the two disorders. Int J Hematol 2010;91:136-139.

4 Bocchia M, Vannucchi AM, Gozzetti A, et al. Insights into JAK2-V617F mutation in CML. Lancet Oncol 2007;8:864-866.

5 Bornhauser M, Mohr B, Oelschlaegel U, et al. Concurrent JAK2(V617F) mutation and BCR-ABL translocation within committed myeloid progenitors in myelofibrosis. Leukemia 2007;21:1824-1826.

6 Cambier N, Renneville A, Cazaentre $\mathrm{T}$, et al. JAK2V617F-positive polycythemia vera and Philadelphia chromosome-positive chronic myeloid leukemia: one patient with two distinct myeloproliferative disorders. Leukemia 2008;22:1454-1455.

7 Campiotti L, Appio L, Solbiati F, et al. JAK2-V617F mutation and Philadelphia positive chronic myeloid leukemia. Leuk Res 2009;33:e212-e213.

8 Caocci G, Atzeni S, Orru N, et al. Response to imatinib in a patient with chronic myeloid leukemia simultaneously expressing p190(BCR-ABL) oncoprotein and JAK2V617F mutation. Leuk Res 2010;34:e27-e29.

9 Conchon MR, Costa JL, Novaes MM, et al. Simultaneous detection of JAK2 V617F mutation and Bcr-Abl translocation in a patient with chronic myelogenous leukemia. Int J Hematol 2008;88:243-245. 
10 Gattenlohner S, Volker HU, Etschmann B, et al. BCRABL positive chronic myeloid leukemia with concurrent JAK2(V617F) positive myelodysplastic syndrome/ myeloproliferative neoplasm (RARS-T). Am J Hematol 2009;84:306-307.

11 Grisouard J, Ojeda-Uribe M, Looser R, et al. Complex subclone structure that responds differentially to therapy in a patient with essential thrombocythemia and chronic myeloid leukemia. Blood 2013;122: 3694-3696.

12 Hussein K, Bock O, Seegers A, et al. Myelofibrosis evolving during imatinib treatment of a chronic myeloproliferative disease with coexisting BCR-ABL translocation and JAK2V617F mutation. Blood 2007;109:4106-4107.

13 Inami M, Inokuchi K, Okabe $\mathrm{M}$, et al. Polycythemia associated with the JAK2V617F mutation emerged during treatment of chronic myelogenous leukemia. Leukemia 2007;21:1103-1104.

14 Inokuchi K, Yamaguchi H, Tamai H, et al. Disappearance of both the BCR/ABL1 fusion gene and the JAK2V617F mutation with dasatinib therapy in a patient with imatinib-resistant chronic myelogenous leukemia. J Clin Exp Hematop 2012;52:145-147.

15 Jallades L, Hayette S, Tigaud I, et al. Emergence of therapy-unrelated CML on a background of BCR-ABLnegative JAK2V617F-positive chronic idiopathic myelofibrosis. Leuk Res 2008;32:1608-1610.

16 Krämer A, Reiter A, Kruth J, et al. JAK2-V617F mutation in a patient with Philadelphia-chromosome-positive chronic myeloid leukaemia. Lancet Oncol 2007;8:658-660.

17 Pardini S, Fozza C, Contini S, et al. A case of coexistence between JAK2V617F and BCR /ABL. Eur J Haematol 2008;81:75-76.

18 Pastore F, Schneider S, Christ O, et al. Impressive thrombocytosis evolving in a patient with a BCR-ABL positive CML in major molecular response during dasatinib treatment unmasks an additional JAK2V617F. Exp Hematol Oncol 2013;2:24.

19 Pingali SRK, Mathiason MA, Lovrich SD, et al. Emergence of chronic myelogenous leukemia from a background of myeloproliferative disorder: JAK2V617F as a potential risk factor for BCR-ABL translocation. Clin Lymphoma Myeloma 2009;9:E25-E29.

20 Qin YW, Yang YN, Li S, et al. Coexistence of JAK2V617F mutation and BCR-ABL translocation in a pregnant woman with essential thrombocythemia. Indian J Hematol Blood Transfus 2014;30:331-334.

21 Tefferi A, Levitt R, Lasho TL, et al. Postimatinib therapy emergence of a new JAK2V617F clone and subsequent development of overt polycythemia vera in a patient with chronic myelogenous leukaemia. Eur J Haematol 2010;85:86-87.

22 Toogeh G, Ferdowsi S, Naadali F, et al. Concomitant presence of JAK2 V617F mutation and BCR-ABL translocation in a pregnant woman with polycythemia vera. Med Oncol 2011;28:1555-1558.

$23 \mathrm{Xu} \mathrm{W}$, Chen B, Tong X. Chronic myeloid leukemia patient with co-occurrence of BCR-ABL junction and JAK2 V617F mutation. Int J Hematol 2014;99: 87-90.

24 Zhou A, Knoche EM, Engle EK, et al. Concomitant JAK2 V617F-positive polycythemia vera and BCR-ABLpositive chronic myelogenous leukemia treated with ruxolitinib and dasatinib. Blood Cancer J 2015;5:e351.

25 Cappetta M, Perez V, Zubillaga MN, et al. Concomitant detection of BCR-ABL translocation and JAK2 V617F mutation in five patients with myeloproliferative neoplasm at diagnosis. Int J Lab Hematol 2013;35:e4-e5.

26 Hussein K, Bock O, Theophile K, et al. Chronic myeloproliferative diseases with concurrent BCR-ABL junction and JAK2V617F mutation. Leukemia 2008;22:1059-1062.

27 Hummel JM, Kletecka MCF, Sanks JK, et al. Concomitant BCR-ABL1 translocation and JAK2(V617F) mutation in three patients with myeloproliferative neoplasms. Diagn Mol Pathol 2012;21:176-183.

$28 \mathrm{Kim}$ YK, Shin MG, Kim HR, et al. Simultaneous occurrence of the JAK2V617F mutation and BCR-ABL gene rearrangement in patients with chronic myeloproliferative disorders. Leuk Res 2008;32:993-995.

29 Laibe S, Tadrist Z, Arnoulet C, et al. A myeloproliferative disorder may hide another one. Leuk Res 2009;33: 1133-1136.

30 Lee YJ, Moon JH, Shin HC, et al. Two CML patients who subsequently developed features of essential thrombocythemia with JAK2-V617F mutation while in complete cytogenetic remission after treatment with imatinib mesylate. Int J Hematol 2013;97:804-807.

31 Mirza I, Frantz C, Clarke G, et al. Transformation of polycythemia vera to chronic myelogenous leukemia. Arch Pathol Lab Med 2007;131:1719-1724.

32 Park SH, Chi HS, Cho YU, et al. Two cases of myeloproliferative neoplasm with a concurrent JAK2 (V617F) mutation and BCR/ABL translocation without chronic myelogenous leukemia phenotype acquisition during hydroxyurea treatment. Ann Lab Med 2013;33:229-232.

33 Pieri L, Spolverini A, Scappini B, et al. Concomitant occurrence of BCR-ABL and JAK2V617F mutation. Blood 2011;118:3445-3446.

34 Veronese L, Tchirkov A, Richard-Pebrel C, et al. A thrombocytosis occurring in Philadelphia positive CML in molecular response to imatinib can reveal an underlying JAK2(V617F) myeloproliferative neoplasm. Leuk Res 2010;34:e94-e96.

35 Wang X, Tripodi J, Kremyanskaya M, et al. BCR-ABL1 is a secondary event after JAK2V617F in patients with polycythemia vera who develop chronic myeloid leukemia. Blood 2013;121:1238-1239.

36 Xiao X, Zhang Y, Zhang GS, et al. Coexistence of JAK2V617F mutation and BCR-ABL1 transcript in two Chinese patients with chronic myelogenous leukemia. Acta Haematol 2011;127:47-49.

37 Soderquist C, Bagg A. Coexistent BCR-ABL1 and JAK2 V617F: converting CML dwarves to ET staghorns with imatinib therapy. Blood 2014;124:2463.

38 Martin-Cabrera P, Haferlach C, Kern W, et al. BCRABL1-positive and JAK2 V617F-positive clones in 23 patients with both aberrations reveal biologic and clinical importance. Br J Haematol 2016;176:135-139.

39 Lugo TG, Pendergast AM, Muller AJ, et al. Tyrosine kinase activity and transformation potency of bcr-abl oncogene products. Science 1990;247:1079-1082.

40 Clarkson B, Strife A, Wisniewski D, et al. Chronic myelogenous leukemia as a paradigm of early cancer and possible curative strategies. Leukemia 2003;17: 1211-1262.

41 Ohsaka A, Shiina S, Kobayashi M, et al. Philadelphia chromosome-positive chronic myeloid leukemia expressing p190(BCR-ABL). Intern Med 2002;41: 1183-1187.

42 Melo JV, Myint H, Galton DA, et al. P190BCR-ABL chronic myeloid leukaemia: the missing link with chronic myelomonocytic leukaemia? Leukemia 1994;8: 208-211. 